\title{
Obtaining Some Polymer Composites Filled with Rice Husks Ash-A Review
}

\author{
Sevdalina Turmanova ${ }^{1}$, Svetlana Genieva ${ }^{1} \&$ Lyubomir Vlaev $^{1}$ \\ ${ }^{1}$ Assen Zlatarov University, Burgas, Bulgaria \\ Correspondence: Sevdalina Turmanova, Assen Zlatarov University, 8010 Burgas, Bulgaria. Tel: 359-56-858-247. \\ E-mail: sturmanova@btu.bg
}

Received: March 19, $2012 \quad$ Accepted: April 10, $2012 \quad$ Online Published: July 29, 2012

doi:10.5539/ijc.v4n4p62 URL: http://dx.doi.org/10.5539/ijc.v4n4p62

\begin{abstract}
Rice husks are an important by-product of rice milling process and are major waste product of the agricultural industry. Rice husk contain nearly $20 \mathrm{mass} \%$ silica, which is present in hydrated amorphous form. They have now become a great source as a raw biomass material for manufacturing of value-added silicon composite products, including silicon carbide, silicon nitride, silicon tetrachloride, magnesium silicide, pure silicon, zeolite, fillers of rubber and plastic composites, cement, adsorbent and support of heterogeneous catalysts. The rice husk was subjected to pyrolysis in fluidized-bed pilot plant in air or nitrogen atmosphere. The controlled thermal degradation of the rice husks in air or nitrogen leads to production of white rice husks ash (WRHA) and black rice husks ash (BRHA) respectively. WRHA contains almost pure ( $\geq 95$ mass $\%$ ) silica in a hydrated amorphous form, similar to silica gel, with high porosity and reactive surface $\mathrm{OH}$ groups. BRHA contains different amounts of carbon and silica in amorphous form with high specific surface area and porosity. The raw rice husks and the obtained pyrolysis products were used as fillers of polypropylene (PP) and tetrafluoroethylene-ethylene copolymer (TFE-E) composites. The kinetics and thermodynamics of water adsorption onto filled polypropylene composites during soaking were studied at different temperatures, quantities and nature of fillers. It was established, that the adsorption kinetics was limited by intra-particle diffusion in plane sheet particles. The sorption process is exothermal in nature and accompanied with decrease of the entropy.

The physicomechanical properties of composite materials were determined. The fillers introduced in polypropylene change the mechanical strength and make the composites brittle. This change is more pronounced for the composites with BRHA and RRH, followed by WRHA. The composites studied showed lower elongation at break. The biggest decrease was observed for the composites with BRHA where $\varepsilon$ decrease from 500 (for the initial PP) to $7 \%$ at filling degree of 20 mass $\%$. The effects of the amount of adsorbed water, temperature and treatment time on the composites tensile properties were estimated. It was found after immersion in water that the composites improve their tensile strength compared to initial non-treated samples. The thermal stability and kinetics of non-isothermal degradation of PP and TFE-E composites filled with 10 or 20 mass \% vigorously grounded and mixed RRH, BRHA, WRHA and Aerosil Degussa (AR) were studied. Using different calculation procedures the most probably kinetic mechanism was found to be described by kinetic equations of $n^{\text {th }}$ order $\left(\mathrm{F}_{\mathrm{n}}\right.$ mechanism). The kinetic parameters were obtained, and a linear dependence between $\ln A$ and $E$ was observed, known also as kinetic compensation effect.

The abundance of a waste from paddy milling industry, as well as its interesting complex of behaviors are prerequisite for success for obtaining of cheap and valuable products and gives a new alternatives for its applications. The production of value added materials from rice husks not only facilitates utilization of an abundantly available agro waste, but also reduces the environmental pollution and solves a serious ecological problem.
\end{abstract}

Keywords: rice husks, pyrolysis, black and white rice husks ash, fillers, polymer composites

\section{Introduction}

The production of rice, one of the major food crops in the world, generates one of the major wastes of the world, namely, rice husks (RH). It is one of the agricultural "waste" materials available in large amounts in rice producing countries, which is amenable for value addition. A number of reviews and monographs (Govindarao, 1980; Bailey et al., 1999; Sun \& Gong, 2001; Kaushik et al., 2001; Chandrasekhar et al., 2003; Babel \& 
Kurniawan, 2003; Liou, 2004; Chuah et al., 2005; Crini, 2006; Muthadhi et al., 2007; Rozainee, 2007) have been dedicated to rice husks and the products obtained from its thermal degradation at different conditions. It is reported that about 0.23 tons of $\mathrm{RH}$ are generated per ton of rice produced. Efforts to utilize it have been handicapped by their tough, woody, abrasive nature, low nutritive properties, and resistance to degradation, great bulk and high ash content. Such efforts have resulted in minor usage, mostly in low-value applications in agricultural areas or as fuel. Little advantage is taken of the RH and pollution is caused in such disposal processes. However, because of the high silicon content in RH, its utilization has been significantly widened in the past few decades. At present, RH and especially rice husks ashes (RHA) obtained after controlled burning of rice husks are the raw materials for the production of a series of silicon-based materials (Sun \& Gong, 2001; Mishra et al., 1986; Della et al., 2002; Watari et al., 2003), including silica (James \& Rao, 1986; Kalapathy et al., 2000, 2002; Zaky et al., 2008), activated carbon (Watari et al., 2006; Kalderis et al., 2008), sodium silicate (Kalapathy et al., 2000; Sekar \& Virutha, 2005), silicon tetrachloride (Basu et al., 1973; Seo et al., 2003), sodium silicofluoride (Sun \& Gong, 2001) and silanes (Acharya et al., 1980; Nandi et al., 1991). The high reactivity and purity of RHA makes it an ideal starting material/silica source for preparing advanced materials like sialon (Sun \& Gong, 2001; Rahnman \& Saleh, 1995), silicon carbide (Krishnarao et al., 1998; Rodriguez-Lugo et al., 2002; Sujirote \& Leangsuwan, 2003), silicon nitride (Kumar \& Godkhindi, 1996; Real et al., 2004), cordierite (Sun \& Gong, 2001; S. Kurama \& H. Kurama, 2008), forsterite (Sun \& Gong, 2001), gehlenite (Sun \& Gong, 2001; Han et al., 1999), pure elemental silicon (Sun \& Gong, 2001; Hunt et al., 1984), magnesium silicide (Acharya et al., 1980; Ghosh et al., 1991), Si-O-C fibers (Sun \& Gong, 2001; Shimokawa et al., 1992), zeolites (Gokhal et al., 1986; Chareonpanich et al., 2004) etc. Recently, RHA has been successfully used as a sorbent of heavy metal ions, dyes and pigments from aqueous solutions (Mohanty et al., 2006; Lakshmi et al., 2009; Sharma et al., 2010) and as a support of $\mathrm{Ni}, \mathrm{Cu}, \mathrm{Cr}$ or $\mathrm{V}$ containing catalysts for various organic reactions and it was found to be preferable over silica gel (Tsai \& Chang, 2000; Chang et al., 2005, 2006; Renu et al., 2008).

In the last two decades, $\mathrm{RH}$ and the products of its thermal degradation are often used as fillers in paper, paint (Chandrasekhar et al., 2003), polymers (Saheb \& Jog, 1999; Chaudhary et al., 2002, 2004; Choi et al., 2006), polymeric composites (Siriwardena et al., 2002; Premalal et al., 2003; Kim et al., 2004; Nassar, 2007), rubber (Ismail \& Mega, 2001; Zurina et al., 2004; Arayapranee et al., 2005), cement (Singh et al., 2001; Jauberthie et al., 2003; Asavapisit \& Ruengrit, 2005), adhesives and fertilizers (Chandrasekhar et al., 2003). By the addition of fillers, the mechanical, thermal, chemical and other properties of the material are improved. Controlled burning of RH in air or inert atmosphere yields two grades of fillers, namely white rice husks ash (WRHA) and black rice husks ash (BRHA). Both these RHA have been used as fillers in polyethylene (Panthapulakkal et al., 2005; Yao et al., 2008), polypropylene (Fuad et al., 1993, 1995; Premalal et al., 2002; Siriwardena et al., 2003; Ismail et al., 2003; Yang et al., 2004, 2007; Fuad et al., 1994; Toro et al., 2005), polystyrene (Ismail et al., 2003) etc. (Siriwardena et al., 2001; 2002). Tremendous opportunities exist in more exhaustive research on the RHApolymer composites, which can lead to the futuristic "organic-inorganic hybrid materials" with specific properties. In this respect, the aim of the present work is to describe the possibility for utilization of raw rice husks and the products of its thermal degradation as fillers in different polymer plastics composites.

\section{Chemical Constituent, Structure and Properties of Raw Rice Husks}

According to the statistical data of Food and Agriculture Organization (FAO), the global annual paddy production reached 628 million tons in 2005 with an additional $1 \%$ increase in 2006 (Yao et al., 2008). These large quantities of RH are available as waste from rice milling industry. These husks are not of commercial interest and cause serious pollution problems. It is necessary, then, to consider the use of this residue in polymer formulations with a clear positive effect to the environment. In nature, RH is tough, insoluble in water, woody and characterized by its abrasive inherent resistance behavior and silica-cellulose structural arrangement. Its major constituents are cellulose, hemicelluloses, lignin, hydrated silica and ash content. The exterior of RH is composed of dentate rectangular elements, mostly silica coated with a thick cuticle and surface hairs, while the mid region and inner epidermis are usually containing a small amount of silica. The chemical constituents are found to vary from sample to sample which may be due to the different geographical conditions, type of paddy, climatic variation, soil chemistry and fertilizers used in the paddy growth (Chaudhary \& Jollands, 2004; Kennedy et al., 2004; Chandrasekhar et al., 2005). Govindarao (1980), in an extensive review, has analyzed all the data reported on the chemical composition of RH from various countries, including western world and Asia, and gives an average composition of dry basis as organic matter $80 \%$ and ash $20 \%$. The chemical analyses of the inorganic part in rice husks showed that the main component is amorphous silica and small amounts of some oxides of alkali, alkali earth metals, aluminum and iron. There are significant variations in the last mentioned compounds, due to the use of different chemical fertilizers in the paddy field in addition to the difference in the 
soil chemistry.

\section{Technologies Available for Rice Husks Thermal Degradation}

Four thermal treatment technologies have been widely used to produce amorphous silica and silica/carbon from RH: muffle furnace, rotary kiln, stepped grate furnace and inclined grate furnace. According to the literature data (Rozainee, 2007; Daifullah et al., 2003; Natarajan et al., 1998; Petro et al., 1987; Bhattacharya et al., 1984; Ganesh et al., 1992; Mansaray et al., 1999; Huang et al., 2001; Armesto et al., 2002; Jiang et al., 2003), the thermal degradation of RH may be carried out under static or dynamic conditions. The products obtained are brittle, amorphous and porous. The major disadvantages of this method for thermal degradation of RH are its high energy consumption, batch-like process, absence of mixing amongst the reactants, low production rate, long reaction time and risk of explosion.

It is impossible to mix the reactants (RH and oxygen) aiming to increase the rates of mass and heat transfer and, therefore, the RH feed has to be spread as a very thin layer inside the furnace to ensure sufficient oxygen transfer on micro-level. This in turn limits the amount of RH that could be processed in any one time. The absence of mixing also results in the formation of ash with intact skeleton-like shape which tends to entrap any unburnt carbon and makes it difficult to be oxidized. Since the process is taking place in a closed system, the absence of free-flowing oxygen results also in incomplete oxidation of carbon in the husks. To prevent the risk of crystallization, the furnace need to be operated at a lower temperature range $\left(400-600^{\circ} \mathrm{C}\right)$, which in turn requires longer treatment periods ( 3 to 6 hours) in order to achieve high carbon conversion efficiency. RH contain a high amount of volatiles, (in the excess of 60 mass \%, wet basis) and the sudden release of these volatiles upon exposure to high temperature in a closed system such as that of the muffle furnace might pose the risk of explosion.

The analysis of literature data showed that products of high quality and economic advantage may be obtained under dynamic conditions using bubbling fluidized bed reactor for burning or pyrolysis of RRH (Rozainee, 2007; Rozainee at al., 2008, Janvijitsakul \& Kuprianov, 2008; Estevez et al., 2009; Fang et al., 2004, Qiaoqun et al., 2005). The fluidized bed technology is selected as preferable for the production of amorphous silica from RH. On the basis of results obtained from previous studies carried out with laboratory equipment, a pilot plant for pyrolysis of RRH with productivity of $100 \mathrm{~kg} / \mathrm{h}$ RRH was built. Figure 1 shows the overall schematic diagram of fluidized bed combustor system.

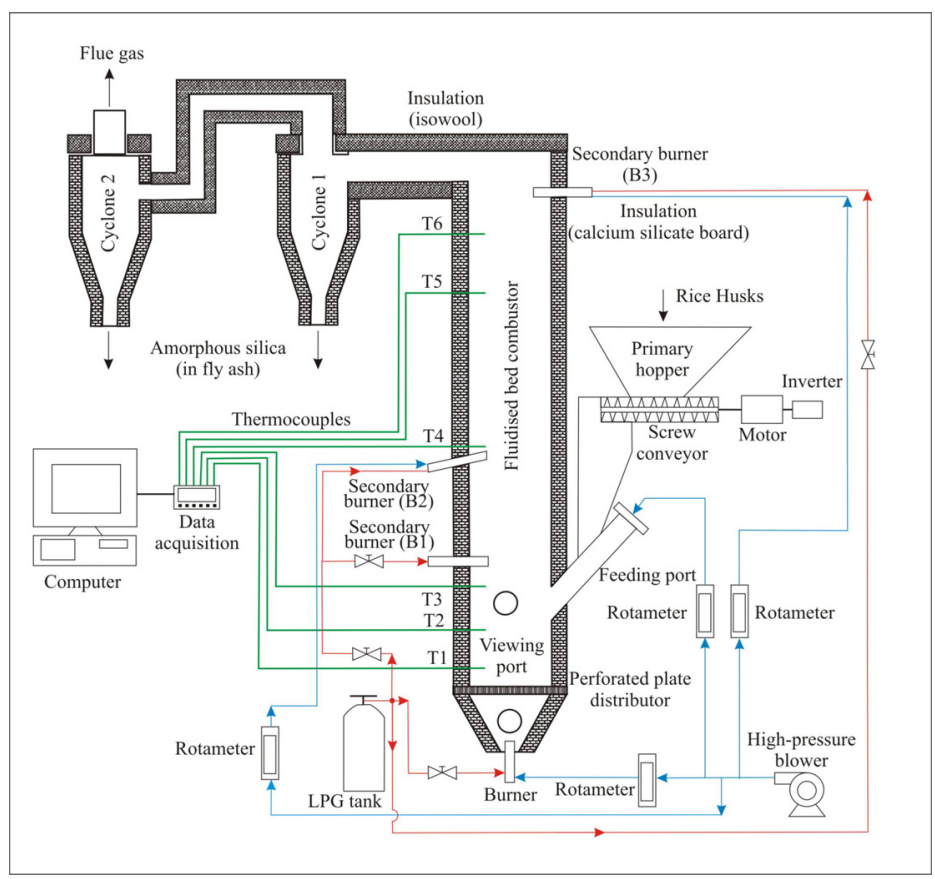

Figure 1. Overall schematic diagram of the 0.3 inner diameter fluidized bed combustor system

Metal serpentines are installed in the volume of the two hot cyclones and in the volume of the uppermost part of the fluidized bed combustor. Inside them, deionized water flows in reverse direction to the exhaust fumes. The water gets heated and vaporizes, which results in high temperature steam. Thus a triple effect is achieved: the 
ecological problem of the utilization of waste RH is solved and BRHA or WRHA, which is a commercial product, and technological steam are obtained.

\section{Physicochemical Characteristics of Rice Husk and the Products of Its Thermal Degradation}

The main physicochemical characteristics of the RH and the products of its thermal degradation in different atmosphere used as fillers of polymers are morphology, crystalline or amorphous state, surface reactivity functional groups, thermal stability and pore structure. The typical morphology of RRH, WRHA and BRHA was examined by a scanning electron microscopy. SEM micrographs of RRH, after combustion in air or after pyrolysis in nitrogen atmosphere at $973 \mathrm{~K}$ are presented in (Genieva et al., 2008; Vlaev et al., 2009; Vlaev et al., 2011). The structure of the pyrolysis product is globular and contained mainly amorphous and porous $\mathrm{SiO}_{2}$ and for BRHA about 5.3 mass\% amorphous carbons with true density $1.8 \mathrm{~g} \mathrm{~cm}^{-3}$ and surface area $241 \mathrm{~m}^{2} \mathrm{~g}^{-1}$.

The XRD patterns of the RRH and pyrolyzed RH, as well as Aerosil A200, are described in (Genieva et al., 2008; Vlaev et al., 2009). All the samples were amorphous, although a broad diffused peak centred at about $2 \theta=22.5^{\circ}$ was observed. Reflexes characterizing cristobalite or tridymite phase were not observed in the samples studied which indicates for the absence of any crystalline phases.

The pore structure of the products of the thermal degradation of RH was studied using low temperature adsorption of nitrogen. On Figure 2 are shown the typical nitrogen adsorption-desorption isotherms of BRHA and WRHA and pore size distribution curves of both samples.
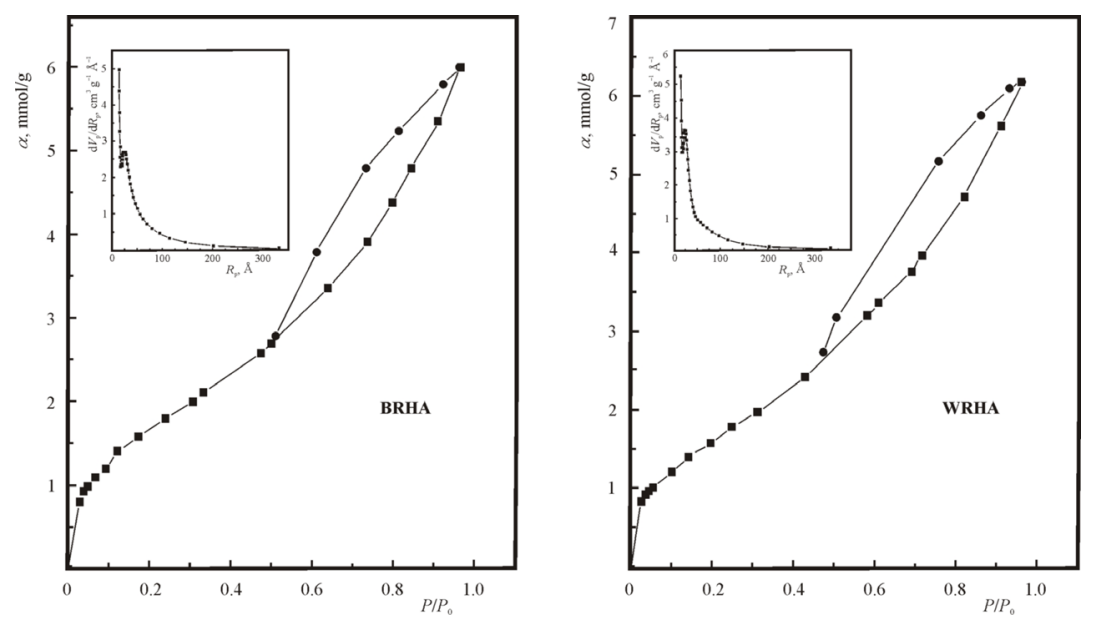

Figure 2. Adsorption-desorption isotherms of BRHA and WRHA and pore size distribution curves

As can be seen from Figure 2, the adsorption isotherms of BRHA and WRHA are of type IV and each had hysteresis loop (associated with capillary condensation) from type H1 according IUPAC classification (Gregg \& Sing, 1982; Tanev \& Vlaev, 1993). According to these observations, both the samples were mainly microporous (mean radius 1.8-2.0 nm) with narrow pore size distribution. It can be seen that the adsorption isotherms and the curves of pore volume distribution of BRHA and WRHA are identical. The uniformity of the adsorption isotherms for WRHA and BRHA shows that the presence of certain amount of amorphous carbon did not result in substantial changes in the amorphous $\mathrm{SiO}_{2}$ porous structure. This is sustained by the fact that the specific surface area of both samples was in the order of $230-240 \mathrm{~m}^{2} / \mathrm{g}$, and pore volume $0.22-0.25 \mathrm{~cm}^{3} / \mathrm{g}$. This was considered to be a sound basis to expect that both products could be used as adsorbents, although it should be kept in mind that hydrophilic WRHA will adsorb predominantly polar molecules while hydrophilic will adsorb mostly non-polar molecules. Taking into account these differences and characteristics of BRHA and WRHA, we carried out studies on the adsorption of diesel fuel and crude oil onto BRHA and WRHA, obtained in our pilot plant fluidized bed reactor.

Infrared spectroscopy provides information on the chemical structure and surface functional groups of the samples. In the IR spectrum of RRH, WRHA and BRHA the different groups in which silicon exists, e.g. siloxane Si-O-Si and silanol Si-OH, are best observed (Genieva et al., 2008;). The RRH are characterized by broad band between 3750 and $2800 \mathrm{~cm}^{-1}$. The $\mathrm{O}-\mathrm{H}$ stretching mode of hexagonal groups and adsorbed water can be assigned to this band. The position and asymmetry of this band at lower wave numbers indicate the presence of strong hydrogen bonds. The adsorption band observed at $2920 \mathrm{~cm}^{-1}$ was related to aliphatic C-H groups and 
the very small peak near $1720 \mathrm{~cm}^{-1}$ was attributed to the $\mathrm{C}=\mathrm{O}$ stretching vibrations of ketons, aldehydes, lactones or carboxyl groups. The weak bands at $1600 \mathrm{~cm}^{-1}$ and $1500 \mathrm{~cm}^{-1}$ correspond to bending vibration of $\mathrm{H}_{2} \mathrm{O}$ molecules physically adsorbed onto rice husks and $\mathrm{C}-\mathrm{H}$ deformation vibrations, respectively. The predominant absorbance peak at $1320 \mathrm{~cm}^{-1}$ was due to stretching vibrations and the one at $450 \mathrm{~cm}^{-1}$ was due to bending vibration of siloxane bonds (Si-O-Si). The peaks between 1200 and $700 \mathrm{~cm}^{-1}$ are attributed to vibration modes of the Si-O network. The IR spectrum of the BRHA obtained did not differ significantly from that of raw rice husks, except for the quite higher intensities of the bands at 1045 and $450 \mathrm{~cm}^{-1}$. This can be explained with the decrease of organic matter content and its transformation into active carbon. The thermal treatment of RH in air, however, resulted in very different IR spectrum. Wide, highly intense peak was observed with maximum at $3420 \mathrm{~cm}^{-1}$, attributed to the stretching vibrations of silanol groups. The bands at 1050,1150 and $790 \mathrm{~cm}^{-1}$ correspond to the Si-O stretching vibration and the bending vibration at $450 \mathrm{~cm}^{-1}$ appeared sharper as the organic matter was no longer present. The positions of this feature are the same as those observed for commercial grade silica. Probably, the silicon atom was initially attached to the oxygen atom in RRH and after the thermal decomposition, the combination of silicon and oxygen atoms lead to the formation of amorphous silica.

The overall decomposition behavior of RH was reported to be due to decomposition of hemicellulose, cellulose and lignin (Liou, 2004). Mansaray and Gally (1999) reported that the hemicellulose and cellulose components of the RH were the main contributors to the evolution of the volatile compounds, while lignin is mainly responsible for the char portion of the products. According to the data obtained from the thermogravimetric analysis, the thermal decomposition of RH in air medium occurred in three main stages of mass loss, namely, removal of moisture (drying); release of organic volatile matters (devolatilization) and oxidation of fixed carbon (slow combustion) (Liou, 2004; Kalapathy et al., 2000; Siriwardena et al., 2002; Mansaray \& Gally, 1999; Chakraverty et al., 1985; Amorim et al., 2004).

The thermogravimetric analysis of WRHA and BRHA obtained by pyrolysis in air and nitrogen atmosphere is described in (Vlaev et al., 2009). The mass loss in the first stage $\left(77-150^{\circ} \mathrm{C}\right.$ ) is accompanied with small endothermic effect. This is about $7 \mathrm{wt} \%$ and is associated with the evolution of adsorbed water in the sample and external water bonded by surface tension. The second and major mass loss of nearly $50 \mathrm{wt} \%$ is attributed to the breakdown of the cellulose constituent to combustible volatiles, water, carbon dioxide and char.

On the basis of TG-curves, Coats-Redfern calculation procedure and the equation of Ginstling-Brounshtein were defined kinetic mechanism and were calculated the kinetics parameters, characterizing non-isothermal degradation of RH in air or nitrogen atmosphere (Vlaev et al., 2009). The kinetic curves have two linear regions: the first one at temperatures lower than $T_{\mathrm{p}}$ (peak temperature in DTG curve) is steeper and the second one at higher temperatures has a smaller slope. For detailed study of the mechanisms of both stages, the values of the activation energy $E$, frequency factor $A$ in Arrhenius equation, change of entropy $\Delta S^{\ddagger}$, enthalpy $\Delta H^{\ddagger}$, Gibbs free energy $\Delta G^{\ddagger}$ for the formation of the activated complex from the reagent and the steric factor $P=\exp \left(\Delta S^{\ddagger} / R\right)$ were calculated. The higher values of $E$ observed at $T<T_{\mathrm{p}}$ show that the initial release of volatile products occurs under kinetic-diffusion control while the much lower values of $E$ at $T>T_{\mathrm{p}}$ indicate that pyrolysis takes place under typical diffusion control. The negative values of the change of entropy mean that the activated complex can be characterized by a much higher "degree of arrangement". Besides, higher degree of "arrangement" was observed in the second stage (higher value of $\Delta S^{\ddagger}$ ). The significantly lower than unity values of the steric factor $P$ in the second stage give enough grounds to classify this stage as "slow". For the first stage, however, the values of $P$ are much closer to unity, so the first stage may be considered as "fast" (Vlaev et al., 2009).

\section{Utilization of the Rice Husks and the Products of Its Thermal Degradation as Fillers of Polymers}

The thermoplastic composites filled with low cost reinforcing natural fillers are widely used in construction and automobile industries and in many consumer goods. The interest towards natural fillers is stipulated by their immanent advantages like availability, low cost, renewability, biodegradability, low density, high specific strength and non-abrasiveness (Panthapulakkal at al., 2005; Sain et al., 2003; Andreas \& Hartmut, 2002). The utilization of agricultural waste products, byproducts, and wood, lignin and cellulose materials solves both technological and ecological problems related with their deposition. Their transformation into usable industrial materials gives economical and ecological benefits (Wang \& Sun, 2002; Yang et al., 2003).

$\mathrm{RH}$ are waste product from rice milling industry and, depending on the geographical region, soil and climate, contain about $67 \%$ carbon, $22 \% \mathrm{SiO}_{2}, 7 \% \mathrm{H}_{2} \mathrm{O}$ and some inorganic components (Bailey et al., 2003; Chandrasekhar et al., 2003; Babel \& Kurniawan, 2003; Liou, 2004). Carbon is present mainly in cellulose, lignin and hemicellulose (Hunt et al., 1984; Sun \& Gong, 2001). The high silica content suggests their use as inorganic 
reinforcing filler for polymers and elastomers (Da Costa et al., 2000; Siriwardena et al., 2002; Ismail et al., 2001). Now various synthetic thermoplastic polymers are used with different reinforcing fillers to improve their mechanical properties obtain suitable characteristics for specific applications.

Using RHA as filler in certain polymers gives composites with better physical, thermal, moisture resistance and processing properties, as well as better economics (Sun \& Gong, 2001; Moreland, 1979; Li et al., 2007). The addition of fillers to polymers is a fast and cheap method to modify the properties of the base polymer. Each filler brings its own characteristics to the matrices and, consequently, to the properties of the composite. The effect of the fillers on the preparation and properties of the composite materials is stipulated by the nature and quantity of the filler and some of its physicochemical properties like particles size, hydrophobicity or hydrophilicity, specific area and surface functional groups, as well as coefficient of distribution in matrix volume. Therefore, composites based on the same filler may have quite different properties depending on the nature, physical and chemical composition and compounding conditions (Saneb \& Jog, 1999; Chaudhary et al., 2002; Chaudhary et al., 2004; Choi et al., 2006). As early as the 1970s, researchers began performing studies on rice husks flour (RHF) and rice husks ashes (RHAs) as filler in rubbers and plastics. In this respect, there are many publications in the literature reporting for the use of natural fibers ( $\mathrm{RH}$, or rice straw fiber) as replacement to man-made fiber in fiber-reinforced composites (Sun \& Gong, 2001; Chandrasekhar et al., 2003; Saneb \& Jog, 1999; Nassar, 2007; Yao et al., 2008; Premalal et al., 2002; Li et al., 2007).

Polypropylene (PP) is used in industry in the form of thermoplastic composites prepared by adding different by nature and content reinforcing fillers, depending on the intended properties of the materials obtained (Pukanszky, 1995). The effect of the fillers on the preparation and properties of the composite materials is stipulated by the nature and quantity of the filler and some of its physicochemical properties like particles size, hydrophobicity or hydrophilicity, specific area and surface functional groups, as well as coefficient of distribution in matrix volume. Therefore, composites based on the same filler may have quite different properties depending on the nature, physical and chemical composition and compounding conditions (Siriwardena et al., 2003).

Yang et al. $(2004 ; 2006 ; 2007)$ studied the morphological and mechanical properties of flour polypropylene composites filled with $10-40 \% \mathrm{RH}$ at different testing rates and temperatures. The authors observed decreased tensile strengths and increased tensile modules with the increase of the degree of filling. The composites showed brittleness at break at high testing rates and plastic deformation at higher temperatures. Advantages of natural fibers over man-made fibers include low density, low cost, recyclability and biodegradability (Li et al., 2007). These advantages make RH potential replacement for glass fiber in composite materials, which can be applied in the plastics, automobile and packaging industries to cut down on material cost.

\subsection{Polypropylene Composites Filled with Rice Husks Ashes}

$\mathrm{PP}$ is a major thermoplastic stereoregular polymer widely used in many industries-construction, automotive, computer components, wire and cable, home appliances, food packing, medical bags, etc. Their versatility is due to their good chemical resistance, low density and a relatively high melting point, so they are useful for storing hot liquids. These polymers represent nowadays about 52 mass \% of the demand for thermoplastics in the world, with a strong increase since. Indeed, these polymers exhibit excellent mechanical and chemical properties, such as weather resistance and are cost effective. Furthermore, they are easy to handle, can be pigmented, easily filled and reinforced in viscous liquid form (Turmanova et al., 2008). Among the mineral fillers for PP, calcium carbonate, talc, clay, silica, glass and carbon fibers are the most often used ones (Sun \& Gong, 2001; Chandrasekhar et al., 2003; Ismail et al., 2003). By the addition of fillers, the mechanical, thermal, chemical and other properties of the plastic are improved. The mechanical properties of composites are the most important because they can be influenced by parameters such as the type of filler, type of matrix, filler concentration, filler dispersion, filler particle size, and the interaction between the filler and matrix. Extensive studies have been carried out during the last decade on the use of WRHA or BRHA as filler materials in PP and PE. Fuad (1994) and Fuad et al. $(1993 ; 1994 ; 1995)$ investigated their use as fillers and the properties of the composites obtained. Flexural modulus and density showed an increase whereas tensile strength, elongation at break and impact strength decreased with the increase of filler content. Poor adhesion between polymer and filler was indicated by SEM studies. They have also described a simple and accurate method for determination of filler material density. The mechanical properties of the composites were of comparable values with the PP composites prepared by filling with commercial Neuburg silica (Fuad et al., 1995). With the increase of the RHA loading, PP and PE composites flexural modulus and density increased, whereas their tensile strength, elongation at break and impact strength decreased. Transformation of the crystalline RHA to amorphous RHA resulted in composites with improved tensile strength. The effect of applying titanate, zirconate and silane couplung agents to RHA in PP composites and the change in their mechanical properties were also studied (Sun \& Gong, 2001; 
Chandrasekhar et al., 2003; Fuad et al., 1995). When a silane-couplung agent is not applied, the melt shear stress and viscosity of PP and PE increased with filler loading. However, if RHA is treated with a silane-coupling agent containing the peroxide bis(tert-butylperoxy)diisopropyl benzene, both the melt shear stress and the viscosity of PP and PE decreased. The degree of viscosity reduction increases with increasing filler, i.e., peroxide concentration. A decrease in viscosity is attributed the peroxide-induced degradation of the matrix (Sun \& Gong, 2001). The effect of coupling agents was also tested and the behavior was compared with two commercial fillersprecipitated silica (grade Vulcasil-S) and carbon black (grade N330). WRHA was better than the BRHA but still inferior to commercial fillers. The tensile and abrasion resistances and hardness of the composites were determined.

\subsubsection{IR Analysis}

The IR absorption spectrum of used PP is presented on Figure 3.

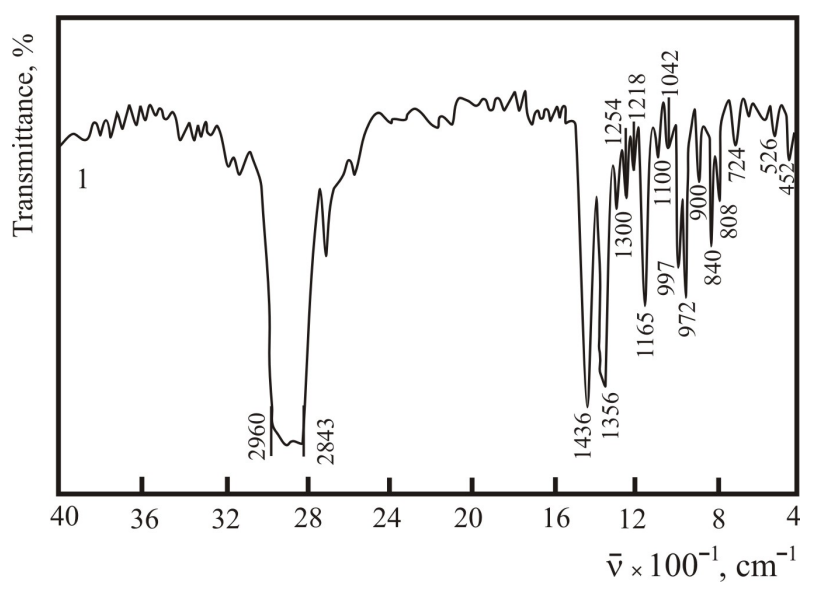

Figure 3. IR absorption spectra of the used PP

A wide intense absorption plateau was observed in the range $2960-2843 \mathrm{~cm}^{-1}$ attributed to the superposition of symmetric and asymmetric stretching vibrations of $\mathrm{CH}_{3}-, \mathrm{CH}_{2}-$ and $\mathrm{CH}$ - groups (Hummel and Scholl, 1968). A number of absorption bands with various intensities were registered in the range $1436-452 \mathrm{~cm}^{-1}$; their assignments are summarized in Table 1.

Table 1. Adsorption bands in the IR spectra of polypropene and their assignment (Hummel and Scholl, 1968) where: vs-very strong; m-medium; vw-very weak; w-weak

\begin{tabular}{ccc}
\hline Bands, $\mathrm{cm}^{-1}$ & Intensity & \multicolumn{1}{c}{ Assigned to } \\
\hline 2956 & vs & $v_{\mathrm{as}}\left(\mathrm{CH}_{3}\right)$ asymmetric stretching vibration \\
2843 & vs & $v_{\mathrm{s}}\left(\mathrm{CH}_{2}\right)$ symmetric stretching vibration \\
1434 & m & $\delta\left(\mathrm{CH}_{2}\right)$ bending vibration \\
1357 & w & $\delta\left(\mathrm{CH}^{2}\right.$ bending vibration \\
1305 & w & $\mathrm{w}\left(\mathrm{CH}_{2}\right)$ wagging vibration \\
1255 & w & $\mathrm{t}\left(\mathrm{CH}_{2}\right)$ twisting vibration \\
1166 & m & $v_{\mathrm{b}}(\mathrm{CC})$ stretching vibration \\
1101 & vw & $v_{\mathrm{b}}(\mathrm{CC})$ stretching vibration \\
1043 & vw & $\mathrm{v}_{\mathrm{a}}(\mathrm{CC})$ stretching vibration \\
998 & m & $\mathrm{r}_{\mathrm{b}}(\mathrm{CH})$ rocking vibration \\
974 & m & $\mathrm{r}_{\mathrm{a}}(\mathrm{CH})$ rocking vibration \\
900 & vw & $\mathrm{v}_{\mathrm{s}}(\mathrm{CC})$ stretching vibration \\
841 & m & $\mathrm{r}(\mathrm{CH})$ rocking vibration \\
809 & w & $v_{\mathrm{s}}(\mathrm{CC})$ stretching vibration \\
528 & vw & $\delta_{\mathrm{a}}(\mathrm{CC})$ bending vibration \\
456 & vw & $\delta_{\mathrm{b}}(\mathrm{CC})$ bending vibration \\
452 & w & $\mathrm{w}(\mathrm{CCH})$ wagging vibration \\
\hline
\end{tabular}


Useful information on the structure of PP filled with different fillers can be obtained by comparing the IR spectra of the fillers, initial and filled PP. In Turmanova et al. (2008) the IR spectra of the composite materials obtained by filling PP with 20 mass\% dispersed fillers of RRH flour, RHAs and for comparison Aerosil A200, Degussa (AR) were studied. The IR absorption spectra of PP filled with 20 mass \% RRH, BRHA, WRHA or AR are presented in Figure 4.

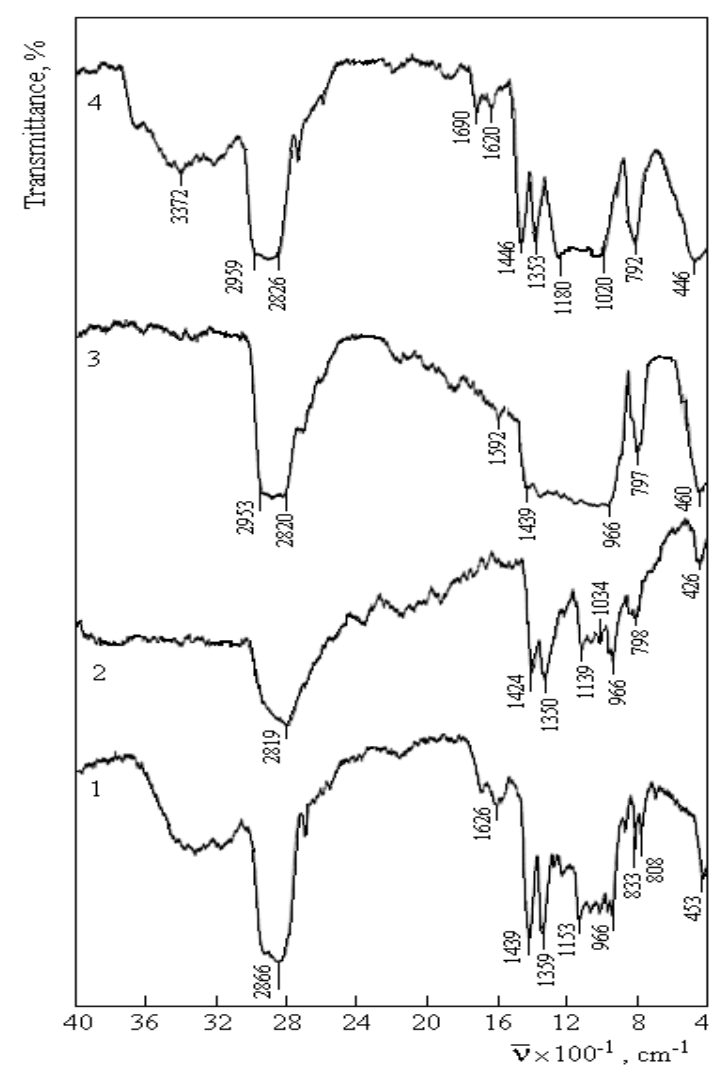

Figure 4. IR absorption spectra of PP filled with 20 mass\%: RRH-1, BRHA-2, WRHA-3 and AR-4

It can be seen from Figure 4 that the IR spectra of filled PP contained, naturally, both the absorption bands characteristic for the initial PP and these characteristic for the filler. Obviously, the IR spectra of PP filled with RRH and BRHA (spectra 1 and 2) are similar in the region 1440-400 $\mathrm{cm}^{-1}$. Unlike spectrum 1, spectrum 2 lacks the absorption bands characteristic for the stretching vibrations of $\mathrm{OH}$ groups and bending vibrations of water molecules in the ranges $3500-3000 \mathrm{~cm}^{-1}$ and $1700-1600 \mathrm{~cm}^{-1}$. The reason for this was considered to be the lack of water and $\mathrm{OH}$ groups in BRHA, which means they are hydrophobic while RRH, are hydrophilic. This substantial difference in the nature of the two fillers could be expected to affect the physicomechanical characteristics of the corresponding composite materials. On the other hand, spectra 3 and 4 are almost identical since the compositions and structures of WRHA and AR are the same-amorphous $\mathrm{SiO}_{2}$. The bands at 3372, 1690 and $1620 \mathrm{~cm}^{-1}$ in spectrum 4 were attributed to stretching and bending vibrations of water molecules sorbed onto more dispersed commercial product (AR). Therefore, it could be expected that the physicomechanical properties of the composite materials obtained with these two fillers would have quite close values (Prachayawarakorn et al., 2005; Turmanova et al., 2008).

\subsubsection{X-Ray Analysis}

The data from X-ray analyses of RRH, BRHA, WRHA and AR showed the absence crystalline peaks and indicate the amorphous nature of the filers (Genieva et al., 2008; Vlaev et al., 2009). The characteristics of composites studied filled with 1 and 20 mass\% ingredients, as well as initial PP, are presented in Table 2. 
Table 2. X-ray structural characteristics of PP composites

\begin{tabular}{cccc}
\hline Sample & $\begin{array}{c}\text { Filler content } \\
C, \text { mass } \%\end{array}$ & $\begin{array}{c}\text { Degree of crystallinity } \\
\alpha, \%\end{array}$ & $\begin{array}{c}\text { Crystallite size, } \\
L_{\theta}, \mathrm{nm}\end{array}$ \\
\hline PP & 0 & 64.1 & 21.4 \\
RRH-1 & 1 & 60.0 & 21.4 \\
RRH-20 & 20 & 53.9 & 21.4 \\
BRHA-1 & 1 & 63.8 & 21.4 \\
BRHA-20 & 20 & 60.9 & 21.4 \\
WRHA-1 & 1 & 64.0 & 21.4 \\
WRHA-20 & 20 & 57.0 & 16.1 \\
AR-1 & 1 & 52.8 & 21.4 \\
AR-20 & 20 & 50.0 & 16.0 \\
\hline
\end{tabular}

The data presented in Table 2 confirmed that the filler nature and degree of filling did not affect the crystallites size in PP. Probably, the filler particles introduced in the polymer do not disturb the degree of arrangement of the macrochains and their disposition in the crystalline formations. As a result, the size of the crystal unit did not change except for the samples filled with 20 mass\% WRHA and AR. The degree of crystallinity was found to decrease with the increase of filler content, which was due to its amorphizing effect.

\subsubsection{Determination of the Dielectric Properties of the Composites}

The dielectric properties of PP make it one of the best electric insulating materials known. Knowing the electric conductivity, dielectric permeability and dielectric losses of PP based composites is interesting for the practice. The measurements the specific electric resistance showed that it was in the range $10^{14-} 10^{15} \mathrm{ohm} \times \mathrm{m}$. It may be concluded, therefore, that the ingredients introduced did not add electric conductivity to the composites, i.e. the materials prepared behave as dielectrics.

It is well known that pure PP has low water adsorption so air moisture and aqueous media do not practically affect its dielectric properties. It is interesting to study the effect of cellulose type of filler (like RRH) on the change of dielectric properties of PP composites. The results obtained for the dielectric parameter studied are summarized in Table 3.

Table 3. Dielectric properties of filled PP composites depending on fillers nature and content

\begin{tabular}{lcc}
\hline Composite & $\begin{array}{c}\text { Dielectric } \\
\text { permeability, } \varepsilon\end{array}$ & $\begin{array}{c}\text { Electric strength } \\
E_{\mathrm{p}}, \mathrm{kV} / \mathrm{m}, \times 10^{-4}\end{array}$ \\
\hline Unfilled PP & 2.8 & 4.61 \\
RRH-1 & 3.2 & 4.48 \\
RRH-3 & 3.2 & 4.17 \\
RRH-5 & 3.2 & 4.30 \\
RRH-10 & 3.3 & 4.52 \\
RRH-20 & 3.4 & 4.60 \\
BRH-1 & 3.0 & 3.68 \\
BRH-3 & 3.1 & 3.41 \\
BRH-5 & 3.1 & 4.01 \\
BRH-10 & 3.1 & 3.36 \\
BRH-20 & 3.2 & 3.31 \\
WRH-1 & 3.1 & 3.66 \\
WRH-3 & 3.0 & 3.45 \\
WRH-5 & 3.1 & 4.08 \\
WRH-10 & 3.2 & 3.33 \\
WRH-20 & 3.2 & 3.51 \\
AR-1 & 3.2 & 4.19 \\
AR-3 & 3.2 & 4.10 \\
AR-5 & 3.2 & 4.39 \\
AR-10 & 3.3 & 4.56 \\
AR-20 & 3.4 & 3.63 \\
\hline
\end{tabular}


As can be seen from Table 3, the values of $E_{\mathrm{p}}$ decreased for all the composites studied compared to initial PP, changing from 4.48 to $3.31 \mathrm{kV} / \mathrm{m}$. This was attributed to redistribution of the field intensity within the dielectric material due to the presence of polar groups on the surface of the fillers used. Another possible interpretation of the tendency observed could be local heating of non-uniform parts of the matrix induced by the formation of aggregates of filler particles and ionization of the air in pores. The filler type did affect this parameter. The dielectric constant $\varepsilon$ increased with the increase of filler content in all the composites used, compared to the initial PP. Since this parameter depended mainly on the introduction of dipole molecules in the dielectric, it could be expected that the introduction of polar $\mathrm{OH}$ groups (RRH and AR) would lead to substantial increase of $\varepsilon$. The data in Table 3 shows that the increase of $\varepsilon$ for the composites based on RRH underwent the highest change-from 3.2 to 3.4 at filling degrees changing from 1 to 20 mass $\%$. The increase for the composites based on WRHA and BRHA was measured to be from 3.0 to 3.2 for filling degrees from 1 to 20 mass\%. These changes can be explained with the influence of the polar groups of the fillers, which induced orientation under electric field, thus changing the value of the dielectric permeability and the dielectric losses. For all the composites studied, $\operatorname{tg} \delta$ changed from $2 \times 10^{-4}$ to $5 \times 10^{-4}$.

Much work (Saneb \& Jog, 1999; Premalal et al., 2003; Panthapulakkal et al., 2005; Premalal et al., 2002; Siriwardena et al., 2003; Toro et al., 2005; Huang et al., 2001; Janvijitsakul \& Kuprianov, 2008; Hamad \& Khattab, 1981; Ismail et al., 2003; Razavi-Noiri et al., 2006) has been done to study the potential RRH flour, WRHA and BRHA as a filler of polyethylene high density (PEHD) or PP composites. The mechanical properties of composites are the most important since they can be influenced by parameters like filler type, matrix type, filler concentration, filler dispersion, filler particle size, and the interaction between the filler and matrix (Premalal et al., 2003). The authors of the present review reported on the use of raw and thermal treated RH and AR as fillers in PP composites and evaluated the phisico-chemical, mechanical and technological properties of the above -mentioned composites filled with different percentage RHA. The AR filled PP composites were used for comparison.

The melt flow index (MFI) is an important property for the thermoplasts since it is directly related with their processing into articles. The MFI in the PP composites decreased with the increase of the filler content. The MFI sharply decreased at filler content up to 3 mass $\%$ and then gradually changed up to degrees of filling 20 mass $\%$ for all the composites studied (Figure 5).

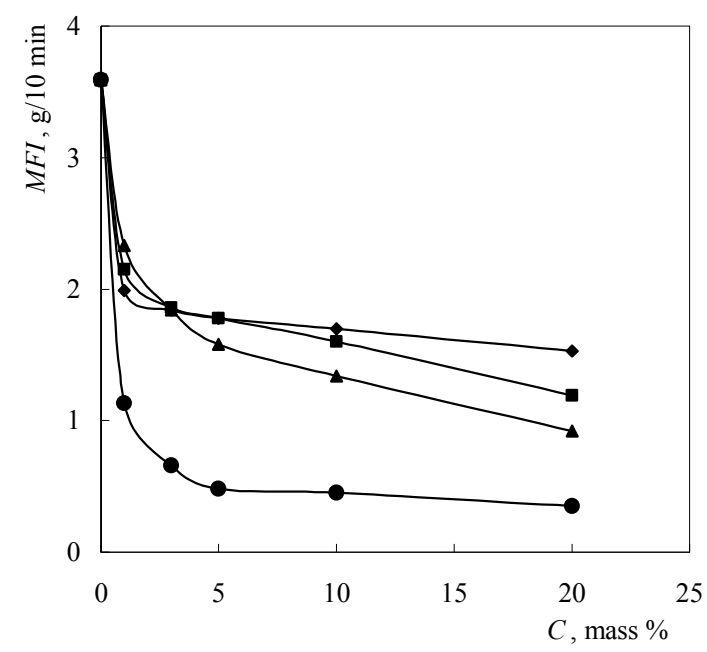

Figure 5. Dependence of MFI, g/10 min on the filling degree C, mass\%: $\bullet$-RRH; a-BRHA; $\mathbf{\Delta}$-WRHA and $\bullet-$ AR

As can be seen from Figure 5, the dependence of MFI on the filler content decreased exponentially and depended on filler nature. The active fillers decreased the MFI to greater extent. The strongest effect on the melt flow exerted the filler AR and smaller decrease of the melt flow was observed by the use of RRH-3.59 and $1.80 \mathrm{~g} / 10$ min, respectively. The WRHA filler, the chemical composition of which is similar to that of AR, decreased the melt flow to greater extent compared to the other two fillers-BRHA and RRH. The differences in the MFI values observed were probably due to the differences in the disperse composition of the fillers. The most finely dispersed one-AR, has the largest active surface and facilitates the generation of strong adhesion interaction at 
the phase boundary between the polymer and the filler which decreased the composite's melt flow index. The composites melt flow indices can be arranged in decreasing order as follows: AR $<$ WRHA $<$ BRHA $<$ RRH $<$ PP. The degree of filling had weak effect on flow ability at filler concentration higher than $\mathrm{C}=10$ mass $\%$.

The results obtained from the determination of Die swell (B) of the extrudates are illustrated in Figure 6.

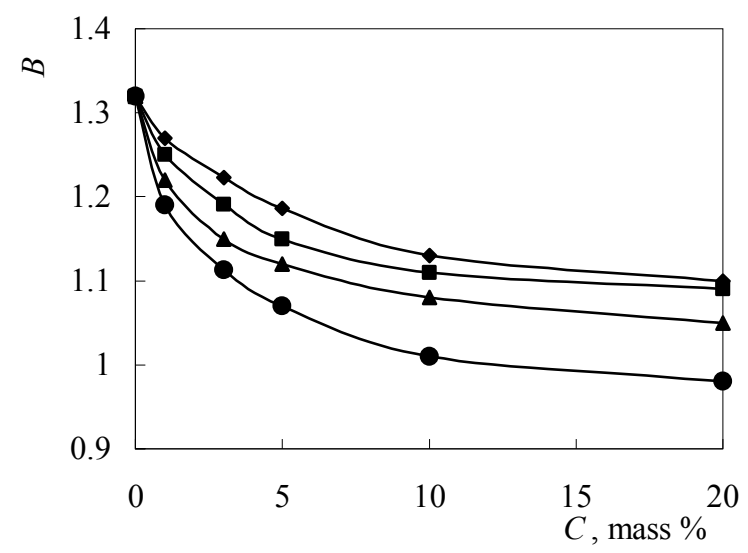

Figure 6. Dependence of Die swell (B) of the composites from the filling degree C, mass\%: $\bullet-R R H, ~-\mathbf{- B R H A}$;

$$
\Delta \text {-WRHA and } \bullet \text {-AR }
$$

It can be seen from Figure 6 that the increase of filler content lead to decrease of Die swell (B) for all the composites studied-from 1.32 for the initial PP to 0.97 for the composites filled with 20 mass $\%$ AR. The smallest values of Die swell for the highest degree of filling of 20 mass\% had the composites with AR, followed by WRHA, BRHA and RRH. This was probably due to the disturbing effect of the filler on the orientation of PP molecules during their flow through the nozzle. Besides, the fillers cause spatial difficulties resulting from physical interactions at the phase boundary, which limit the mobility of PP macromolecules and decrease the flowability. The values of Die swell (B) correlated well with the flow abilities of the composites. The lowest values of Die swell (B) had the composites based of AR, followed by WRHA, BRHA and RRH at the highest degree of filling (20 mass $\%$ ).

The dependence of composites densities on the filling degree is presented in Figure 7. As it was expected, the densities of the composites increased with filler content since the fillers have higher densities compared to the initial PP matrix. The composites based on WRHA, even at 5\% filling, showed higher values of density compared to those filled with BRHA and RRH. This can be explained with the higher density of the ingredient WRHA.

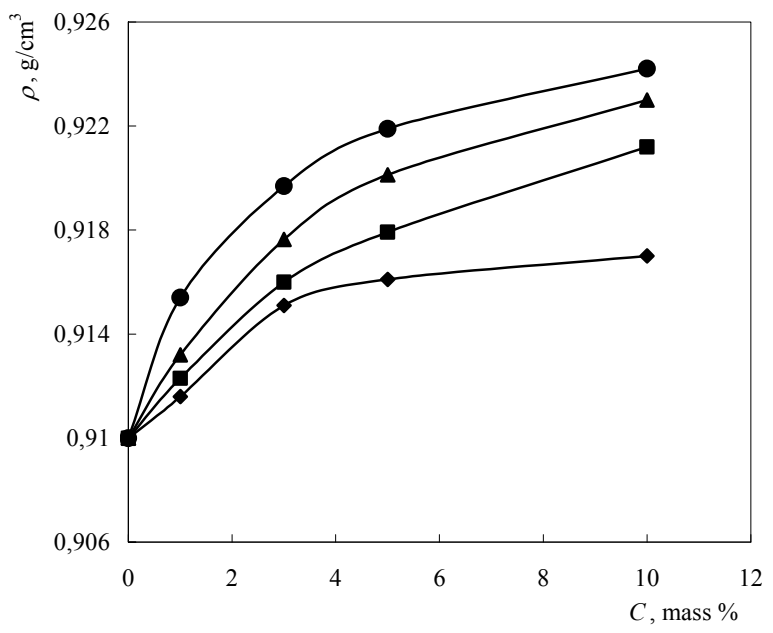

Figure 7. Dependence of the density of composites $\rho, \mathrm{g} \mathrm{cm}^{-3}$ from the filling degree $C$, mass $\%$ : $\checkmark$ RRH; BRHA; $\triangle$-WRHA and $\bullet$-AR 
Figure 7 shows that the dependence of $\rho$ on $C$ was an increasing exponent. The values determined were lower than the additive dependence observed for PP and the fillers used. These differences can be explained with the amorphizing effect of the fillers on the PP matrix. The increase of the filler content was proved to reduce flow ability and the strongest effect was observed for the composites filled with AR. Technological properties closest to these of the initial PP had the composites filled with RRH. The filler type and its concentration did not exert significant effect on the dielectric properties of the composites obtained. The density of RH filled composites increased with the ingredient content. The highest density at $C=5$ mass\% showed the WRHA filled samples and the lowest-these filled with RRH (Turmanova et al., 2008).

\subsubsection{Water Absorption Test}

All the polymers sorb water in a humid atmosphere and when immersed in water. The amount of water adsorbed by non-polar polymers containing filler depends mainly on the nature of the fillers. Natural fillers have an undesirable property, namely, hygroscopicity because of their hydrophilic nature. The moisture adsorption by composites containing natural fillers has several adverse effects on their properties, thus affecting their longterm performance. In many of the applications of the PP and its composites, the material is exposed to water and atmospheric moisture for long periods. This can lead to loss of adhesive strength due to weakening of the product at the interface. This damage results from the diffusion of water molecules throughout the polymer chains causing plasticization, chain rupture, and chemical degradation. The knowledge of water and water vapor sorption in composites and in polymer matrices is considered to be of utmost importance (Prachayawarakorn, 2005). Therefore, it is important to study in detail the water adsorption behavior in order to evaluate not only the consequences that the water absorption may have, but also how this water uptake can be minimized in some way. In other cases, when the filler is hydrophilic material, the addition of this filler into PP matrix changes the water and water vapor sorption properties of PP and makes the composite a water and water vapor-sorbing material. In this case, the PP filled composite can be used where a desiccating packaging material is needed. The kinetics and thermodynamics of water adsorption as well as the comparison of water absorption and mechanical behaviors of polypropylene composites filled with RHA are studied in (Turmanova et al., 2008; Vlaev et al., 2009). The results reported in these works concern the study on the kinetics and thermodynamics of adsorption of water PP composites filled with different by quantity $(1,3,5,10$ or 20 mass $\%)$ and nature (RRH, WRHA, BRHA or AR) fillers and immersed in water.

The water absorption behavior of filled polymer composites was studied as function of the following factors: functionality, polarity, specific surface area and filler content, soak duration in water and the temperature of treatment. As a non-polar polymer, PP is characterized by insignificant water absorption. For example, initial PP contained 1.0 mass $\%$ absorbed water at equilibrium at $25^{\circ} \mathrm{C}$ and 0.25 mass $\%$ at $90^{\circ} \mathrm{C}$. The lignocellulosic fillers are hydrophilic which limits their applicability. On the other hand, the hydrophilic nature of the filler makes the composites very sensitive towards water absorption, which decreases the mechanical properties to a great extent. Therefore the fillers must be dried before being processed

The influence of the amount of absorbed water on the tensile properties of the PP composites was estimated and Figure 8 shows the kinetic curves of water absorption at $25^{\circ} \mathrm{C}$ by PP composites containing amounts of RRH filler.

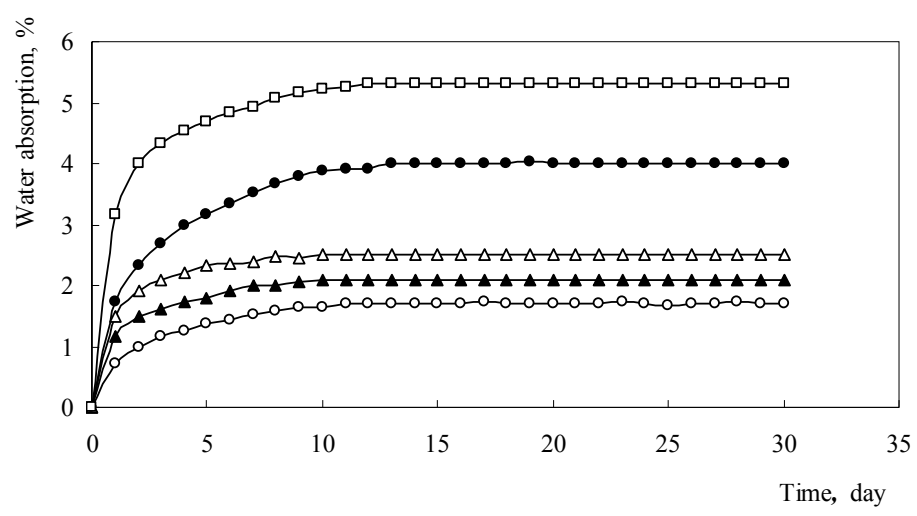

Figure 8. Dependences of water absorption on soaked time at $25^{\circ} \mathrm{C}$ of PP-RRH composites with different filler content: $\circ-1 ; \boldsymbol{\Lambda}-3 ; \Delta-5 ; \bullet-10$ and $\square-20$ mass $\%$ 
As can be seen from Figure 8, the increase of filler loading into the composites resulted in increased equilibrium uptake values, but equilibrium was reached very slowly (as long as 10 days). It means that the non-porous structure of the composites and the diffusion character of water sorption impede the process of absorption.

The kinetic curves of water absorption at the highest studied temperature are presented in Figure 9.



Figure 9. Dependences of water absorption on soaked time at $90^{\circ} \mathrm{C}$ of PP-RRH composites with different filler content: $\circ-1 ; \mathbf{\Delta}-3 ; \Delta-5 ; \bullet-10$ and $\square-20$ mass $\%$

Figure 9 shows that the absorption equilibrium was reached much faster at higher temperature (10 hours) and the amount of sorbed water was lower than that observed at $25^{\circ} \mathrm{C}$. According to the Le Chatalier's principle, the absorption process should be exothermal. Figures 8 and 9 clearly show that the water uptake increases with the increase of the weight percent of RRH filler content. This is due to the fact that, with increase in the RRH flour, the number of free $\mathrm{OH}$ groups cellulose also increases, which in turn makes the composites more hydrophilic. These free $\mathrm{OH}$ groups come in contact with water at different temperatures and form hydrogen bonding, which results in weight gain in the composites. Comparing the kinetic curves shown in Figure 10 can assess the importance of the filler nature for the absorbance of the filled composites.

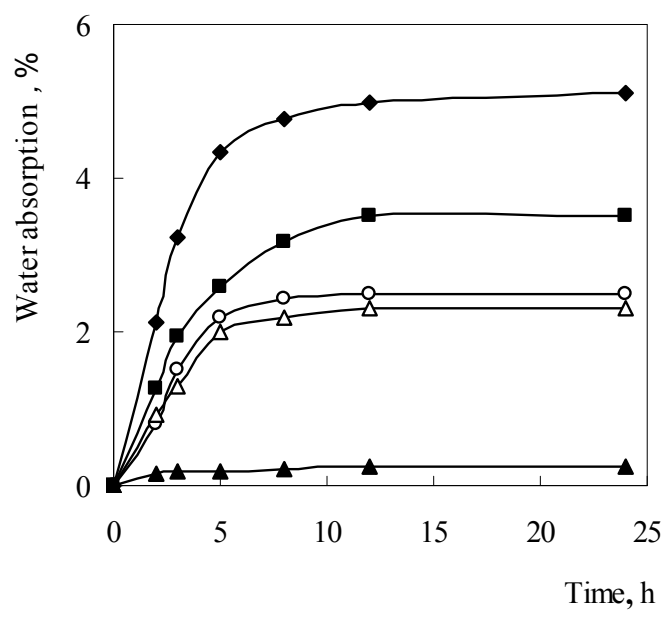

Figure 10. Dependences of water absorption as a function of immersion time at $90^{\circ} \mathrm{C}$ of PP- $\boldsymbol{\Delta}$ and $\mathrm{PP}$ composites filled with 20 mass\%: BRHA- $\Delta$; WRHA-०; AR-m and RRH-॰

It can be seen from Figure 10 the highest sorption capacity had PP filled with RRH and the lowest-the initial PP. It means that the former had the highest hydrophilicity and the latter-the lowest one, as PP is basically a hydrophobic polymer. The samples filled with WRHA or BRHA showed similar hydrophilicities since the filler surface is covered with carbon matter, which is slightly hydrophilic. The higher absorption capacity of the sample filled with AR was due to the opportunity for rehydration of the amorphous $\mathrm{SiO}_{2}$. 


\subsubsection{Tensile Test}

Several main factors shosuld be taken into account when designing the composites made of RRH, WRHA, BRHA, AR and PP. The most important factor determining the possibility to fill PP is the good adhesion between the surfaces of the filler and the polymer. The interaction of PP with the RH products used for the present study is the main condition, which should be met to improve the tensile characteristics. The best adhesion can be observed under strong adsorption interaction between the PP and filler. The formation of physical bonds between PP and RH affects the mobility of the polymer chains near the surface. For the formation of physical bonds between the polymer and the filler, the active centers should be present. Their role in PP is played by some side methyl groups, as well as deformed locations in the macromolecule. The formation of adsorption bonds between the surfaces of PP and the filler leads to additional rearrangement and significant restriction of polymer chain mobility near the surface. Since the surfaces of the fillers used-AR, WRHA and BRHA are quite large, then the PP chains mobility will be more restricted and the packing of the macromolecules will be changed to greater extent, which would exert significant effect on the mechanical properties of the polymer. The tensile strength and elongation at break, values of Young's module and energy to break point of all composites are presented in Table 4 and Figures 11 to 14 .

Table 4. Values of Young's modulus and energy of break point of non-soaked and soaked in water at 25 or $90^{\circ} \mathrm{C}$ PP composites filled with different by nature and quantity fillers

\begin{tabular}{lcccccc}
\hline & \multicolumn{2}{c}{ Energy of break point, J } & \multicolumn{3}{c}{ Young's modulus, MPa } \\
Composite & $\begin{array}{c}\text { Non- } \\
\text { soaked in } \\
\text { water }\end{array}$ & $\begin{array}{c}\text { Soaked } \\
1 \text { month at } \\
25^{\circ} \mathrm{C}\end{array}$ & $\begin{array}{c}\text { Soaked } \\
24 \mathrm{~h} \\
\text { at } 90^{\circ} \mathrm{C}\end{array}$ & $\begin{array}{c}\text { Non- } \\
\text { soaked in } \\
\text { water }\end{array}$ & $\begin{array}{c}\text { Soaked } \\
1 \text { month at } \\
25^{\circ} \mathrm{C}\end{array}$ & $\begin{array}{c}\text { Soaked } \\
24 \mathrm{~h} \\
\text { at } 90^{\circ} \mathrm{C}\end{array}$ \\
\hline Unfilled PP & 8.5 & 4.8 & 4.8 & 598.0 & 591.7 & 435.0 \\
RRH-1 & 0.75 & 0.58 & 1.03 & 604.5 & 555.8 & 430.4 \\
RRH-3 & 0.24 & 0.33 & 0.51 & 605.5 & 679.2 & 565.0 \\
RRH-5 & 0.23 & 0.16 & 0.52 & 605.3 & 627.6 & 571.3 \\
RRH-10 & 0.18 & 0.13 & 0.30 & 613.0 & 757.4 & 648.3 \\
RRH-20 & 0.09 & 0.11 & 0.18 & 632.9 & 782.0 & 657.9 \\
WRHA-1 & 2.16 & 0.84 & 2.02 & 600.5 & 645.0 & 479.4 \\
WRHA-3 & 0.97 & 0.79 & 1.16 & 607.7 & 672.3 & 481.6 \\
WRHA-5 & 0.70 & 0.76 & 1.34 & 608.8 & 784.5 & 539.9 \\
WRHA-10 & 0.53 & 0.58 & 1.05 & 610.4 & 781.6 & 540.0 \\
WRHA-20 & 0.19 & 0.28 & 0.42 & 733.5 & 871.0 & 580.3 \\
BRHA-1 & 1.09 & 0.67 & 0.67 & 498.0 & 578.7 & 468.9 \\
BRHA-3 & 0.58 & 0.43 & 0.77 & 505.5 & 728.2 & 522.8 \\
BRHA-5 & 0.20 & 0.34 & 0.54 & 506.1 & 759.1 & 533.6 \\
BRH-10 & 0.19 & 0.27 & 0.32 & 609.0 & 792.3 & 599.7 \\
BRHA-20 & 0.07 & 0.07 & 0.10 & 692.4 & 798.7 & 704.9 \\
AR-1 & 1.86 & 1.27 & 0.97 & 601.1 & 579.3 & 533.0 \\
AR-3 & 0.64 & 0.90 & 0.77 & 702.7 & 623.1 & 540.4 \\
AR-5 & 0.45 & 0.34 & 0.47 & 717.6 & 644.5 & 543.4 \\
AR-10 & 0.20 & 0.37 & 0.49 & 735.6 & 680.6 & 589.3 \\
AR-20 & 0.14 & 0.25 & 0.42 & 744.8 & 688.2 & 662.2 \\
\hline
\end{tabular}

The Young modulus of all the composites increased with the filler content conforming to the regular behavior of thermoplastics filled with solid fillers. This is explained by the secondary phase of filler particles introduced which play the role of mechanical limit. Besides, the higher moduluses of these solid fillers compared to that of the flexible PP macromolecules among which the fillers are dispersed could also contribute to the reinforcing effect. The higher Young moduluses of the composites filled with AR and WRHA compared to those filled with RRH and BRHA at the same filling degrees could be explained with the stronger restriction of the mobility and deformation of the matrix. The Young moduluses showed a tendency to increase with the decrease of filler particles size while the elongation at break decreased. This is probably due to the larger contact area and better dispersion of the particles throughout the polymer matrix. 


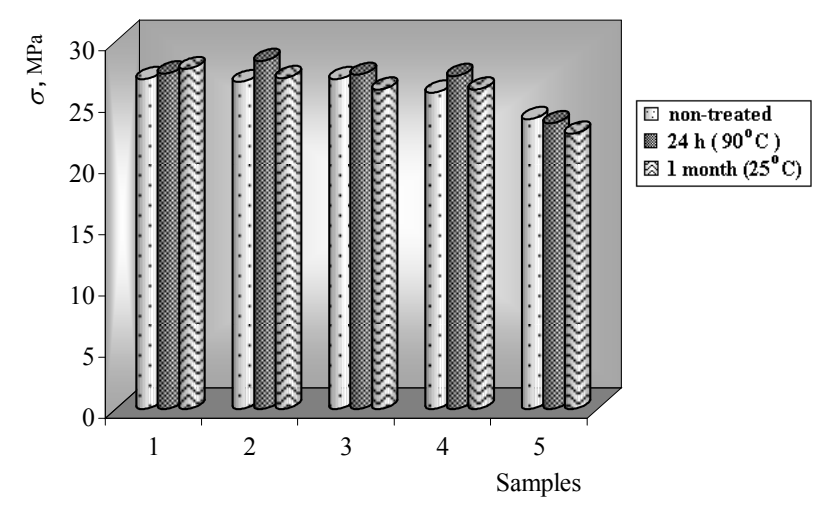

Figure 11. Dependence of the tensile strength of PP-RRH composites with different filling degree $C$, mass\%: 1-1; $2-3 ; 3-5 ; 4-10$ and $5-20$ mass $\%$

The values of $\sigma$ determined for non-filled PP were $\sigma=27.9 \mathrm{MPa}$ (non-treated), $\sigma=27.2 \mathrm{MPa}\left(24 \mathrm{~h}, 90^{\circ} \mathrm{C}\right)$ and $\sigma$ $=25.5 \mathrm{MPa}\left(1 \mathrm{month}, 25^{\circ} \mathrm{C}\right)$.

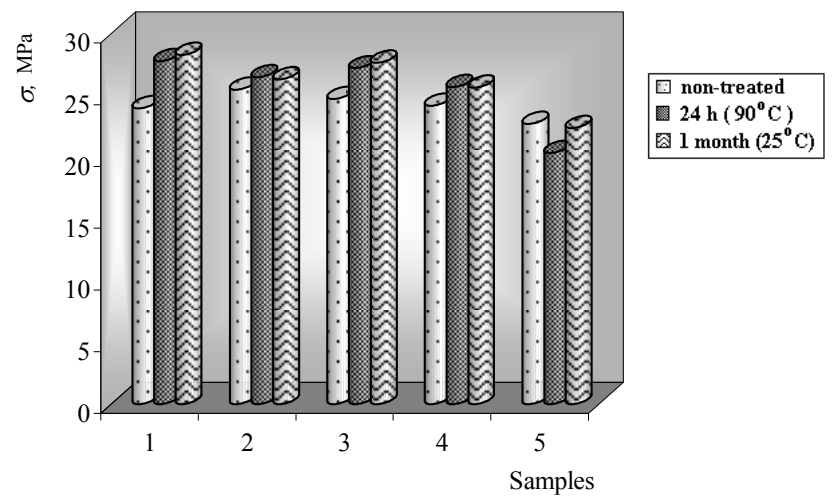

Figure 12. Dependence of the tensile strength of PP-WRHA composites with different filling degree $C$, mass\%: $1-1 ; 2-3 ; 3-5 ; 4-10$ and $5-20$ mass $\%$

The results presented in Figures 11 and 12 reveal reduced strength at filler contents above 10 mass\%. Such behavior has been observed also for some thermoplastic composites filled with agriculture derivatives (Siriwardena et al., 2003; Ismail et al., 2005), as is the case discussed here. This is basically due to intramolecular adhesion interactions between the filler and the matrix. RRH, WRHA and BRHA ingredients contain amorphous aggregated structures with various particles sizes. AR also has amorphous structure. With the increase of filler content, the weak zones between the filler particles and the matrix become more and this decreases the tensile strength of the material. On the other hand, the increase of filler content leads to formation of bigger agglomerates of filler particles. When the degree of agglomeration increases, the interactions between the filler and the matrix become weaker and, as a result, the values of the tensile strength decrease. The composites filled with RRH and AR had higher tensile strength compared to these filled with WRHA and BRHA. Similar results have been reported by Fuad (1994). The lower average particle size stipulates higher tensile strength. AR is a commercial product well known for its reinforcing effect on the filled material. Its particle size is smaller than that of RRH, WRHA and BRHA. Therefore, the contact area with the polymer matrix is expected to be the highest. Thus, under deformation at low rates, the transmission of the stress from the matrix to the filler could be more effective which would give higher tensile strength at filling degrees up to 10 mass\%.

The introduction of the four ingredients gave reduction of the elongation at break. As can be seen from Figures 13 and 14 the highest decrease was observed by the introduction of 20 mass\% BRHA which resulted in decrease of the elongation at break from 500 to $7 \%$. WRHA filled composites showed higher elongation at break compared to the others for all the range of filling degrees studied. They had also higher energy to break point. It 
suggests that these composites are stronger than the others. The interesting phenomenon observed confirmed that WRHA could improve the modulus and strength of PP since the composite material retains acceptable mechanical strength at filling degrees up to $10 \%$, which is quite important for the application of these materials.



Figure 13. Dependence of the elongation at break of polypropene-RRH composites with different filling degree $C$, mass\%: $1-1 ; 2-3 ; 3-5 ; 4-10$ and 5-20 mass\%

The values $\varepsilon$ determined for non-filled PP were $\varepsilon=598 \%$ (non-treated), $\varepsilon=297.8 \%\left(24 \mathrm{~h}, 90^{\circ} \mathrm{C}\right)$ and $\varepsilon=303.7$ $\left(1\right.$ month, $25^{\circ} \mathrm{C}$ ).

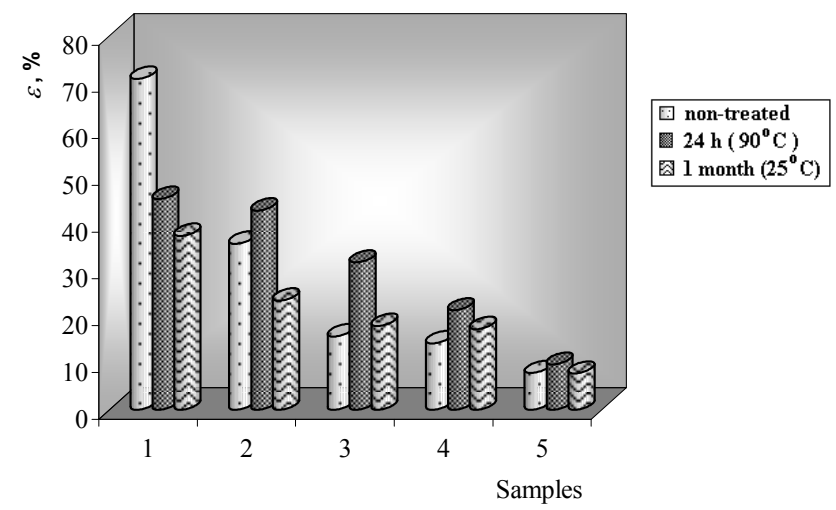

Figure 14. Dependence of the elongation at break of PP-BRHA composites with different filling degree $C$, mass\%: $1-1 ; 2-3 ; 3-5 ; 4-10$ and 5-20 mass\%

PP is well known neck-forming polymer and its breaking is preceded by cold flow. The introduction of various fillers in its matrix changes the shape of the stress-strain curves and the changes depend on the nature and quantity of the filler. The composites containing up to 10 mass\% WRHA showed similar stress-strain behavior with significant decrease of the stress at yield and elongation at break. In these composites, the deformation increased linearly with stress and lead to cold flow followed by elongation at the same deformation and formation of neck before the break. Similar curves were obtained by Siriwardena et al. (2003). At higher filling degrees-up to 20 mass $\%$, all the composites studied had similar behavior with further decrease of the stress at yield and elongation at break. The introduction of AR up to 10 mass\% resulted in fractures and breaking of the samples almost immediately after the yield point was reached, without formation of a neck. This is typical for brittle break while the composites filled with 20 mass\% AR showed actually brittle break of a polymer material. The experimental curves showed that the introduction of filler leads to change in the breaking behavior and makes the composites brittle. This change was more pronounced for the composites with BRHA and RRH, followed by these filled with WRHA and AR.

The figures from 11 to 14 illustrate the changes in tensile strength and elongation at break values, respectively, for all the samples studied under the conditions described above. According to the discussion, AR has better adhesion to the PP matrix than RRH, BRHA and WRHA, which was attributed to the smaller size and better dispersion of its particles in the initial polymer phase. The other fillers are characterized by stronger tendency to 
agglomerate, which stipulates worse intramolecular adhesion interactions between the filler and the matrix. The enlargement of these agglomerates leads to easier translation of crazes and defects and stipulates the breaking of the composite. The microcrazes evolving in filled PP reach the ingredient particles and, therefore, their further evolution is accompanied by increase of stress. This, in turn, increases the average stress necessary to break the material. The energy at break changes its values (Table 4) and shows a tendency to decrease. At temperature of $25^{\circ} \mathrm{C}$, the PP matrix probably has some kind of protection against the direct interaction between the molecules of water and filler. Therefore, the distribution of the stress from the matrix to the filler is still effective enough. Vice versa, various interactions between the molecules of water and filler take place at higher temperatures. This affects the transmission and distribution of the stress, thus changing composite properties. The soaking of the samples in water for $24 \mathrm{~h}$ and 1 month gave noticeable differences in the tensile properties of all the composites studied over the interval of filling. The careful examination of this change revealed interesting phenomena and tendencies.

The composites with WRHA and BRHA showed certain "Reinforcing effect" after soaking in water. The Young modulus (Table 4) and tensile strength increased (Figures 11, 12) and the elongation at break (Figures 13, 14) also was higher compared to the initial non-treated samples, especially at degrees of filling above 3 mass\%. Similar results were obtained for the composites filled with RRH and AR. The RRH filled composites showed slight increase of the tensile strength up to 10 mass\% filler content and increase of the elongation at break while these filled with AR-slight increase of Young modulus and tensile strength with the increase of filler content. The AR filled composites had lower values of the elongation at break up to 3 mass $\%$ degree of filling and brittle break under both conditions-before and after soaking in water. The composites containing more than 5 mass\% AR showed higher elongation at break after soaking in water $\left(24 \mathrm{~h}, 90^{\circ} \mathrm{C}\right.$ and 1 month, $\left.25^{\circ} \mathrm{C}\right)$ compared to the initial non-treated samples. The WRHA filled composites are characterized by insignificant increase of the elongation at break from 3 to 20 mass $\%$ degree of filling.

This phenomenon, which is known as antiplastization, may be responsible for the increase in tensile strength (Sharma et al., 2000; Ismail \& Mega, 2001; George et al., 1998). The increase of the elongation at break of polymer composites filled with hydrophilic fillers after absorption of water is elucidated by the plasticization action of water. However, this effect is accompanied by reduction of the tensile strength. In our study, the tensile strength was also found to increase after immersing the composites in water. The increase of the values of both properties suggests that the absorption of water molecules leads to stronger intermolecular interactions fillermatrix or improved reinforcement accompanied by cross link formation.

Probably, water can act as plasticizer or antiplasticizer for thermoplastic composites when it is at certain concentrations in them, as it has been reported in Sharma et al. (2000). These authors have shown also that if the water molecules concentration is below certain threshold value, water acts exerts antiplasticizing effect, which increases the tensile strength observed in our study. Other authors have mentioned such results for similar filled composites immersed in water at the same conditions, too (Sharma et al., 2000; Ismail \& Mega., 2001; George et al., 1998). This effect is known as the antiplasticizing effect of the water molecules. But probably, there may be optimum water content above which the properties may be adversely affected. Therefore, in requires further indepth investigation on the effect of water absorption on the mechanical properties of these types of composites.

RH and RHAs are used as fillers in different polymer composites. Siriwardena et al. $(2001 ; 2002)$ studied the mechanical and morphological properties and water adsorption of WRHA filled polypropylene/ ethylenepropylene-diene terpolymer thermoplastic elastomer composites. Incorporation of WRHA improved the tensile modulus and flexural modulus and decreased tensile strength, elongation at break, tear strength, and toughness of obtained composites. The water adsorption behavior of WRHA and silica filled ethylene-propylenediene-terpolymer/polypropylene ternary composites was studied with special attention to filler type, test specimen preparation and dynamic vulcanization of elastomer phase (Siriwardena et al., 2002). The influence of final water uptake on tensile properties of the composites was also studied. WRHA filled composites and molded composites exhibit lower water uptake compared to silica filled composites. All vulcanized composites showed lower water uptake than the non-vulcanized composites. After the immersion period in water, tensile properties of non-vulcanized composites were almost unaffected, while vulcanized composites exhibited an increase in the tensile properties. Ismail et al. (2001; 2003; Ismail \& Chung, 1999; Ismail \& Mega, 2001; Nizam \& Khalil, 2001) investigated the effect of a compatibilizer agents on the mechanical, water adsorption and morphological properties of polypropylene/natural rubber blends filled with WRHA. The incorporation of WRHA improved tensile modulus but decreased tensile strength, elongation at break and stress at yield. Water adsorption increased with filler loading. However, the presence of compatibilizer agents had affected the water resistance of the composites. The studies in this direction provide possibilities for controlled synthesis of composites filled with 
natural ingredients, combining the properties of the polymeric phase (matrix) and fillers to obtain products with practically valuable properties. In conclusion, it may be believed that the RHA-polymer composites can lead to the futuristic "organic- inorganic hybrid materials" with special properties.

\subsection{Tetrafluoroethylene-ethylene Copolymer Composites}

Extreme operation conditions in a number of cases require the use of polymers and composite materials based on them with very special chemical content, structure and properties, such as fluoropolymers and especially tetrafluoroethylene-ethylene copolymers (TFE-E). Among the TFE-E copolymers, these with equimolar monomer composition are the most widely used. This copolymer has high melting and operation temperatures which are by $50-70^{\circ} \mathrm{C}$ lower than that of polytetrafluoroethylene (PTFE). The alternating TFE-E copolymers possess high thermal stability in air even at $500^{\circ} \mathrm{C}$ and their specific property is the high radiation resistance1000 кGy (Garbuglio et al., 1974; Weis \& Wilke, 1992; Feng \& Chan, 2003; Liu et al., 2007). For the first time, the use of RHA as fillers of TFE-E copolymer was described in (Atanassov et al., 2010). The TG curves taken at heating rate of $6 \mathrm{~K} / \mathrm{min}$ of the initial TFE-E copolymer and its composites containing 10 mass\% WRHA, BRHA or AR are presented in Figure 15.

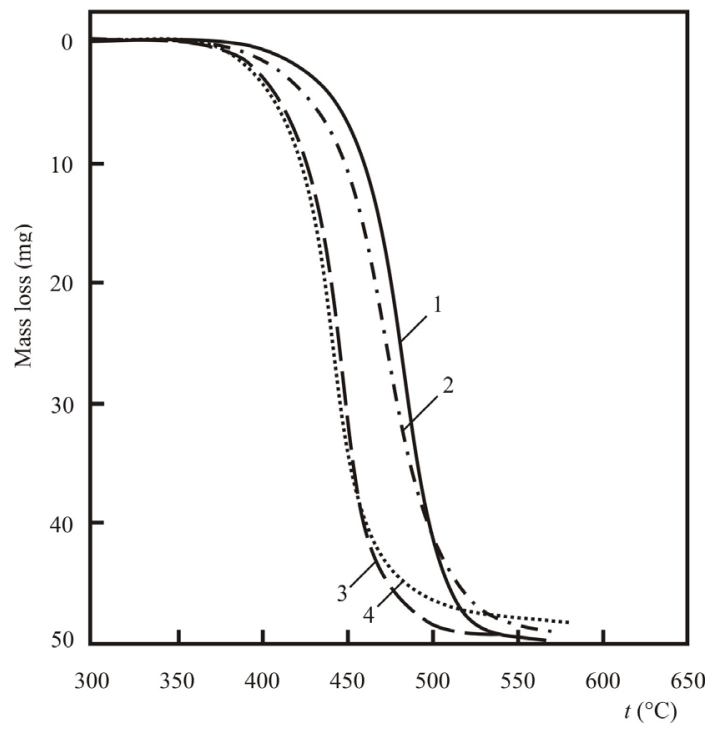

Figure 15. TG curves of thermal degradation of: 1-TFE-E copolymer, 2-TFE-E + BRHA, 3-TFE-E + WRHA and 4-TFE-E + AR

As can be seen from Figure 15, the thermal degradation of the initial TFE-E copolymer (curve 1) started at the highest temperature and the corresponding TG curve for the sample filled with 10 mass\% BRHA (curve 2) was close to it while the TG-curves for the copolymers filled with 10 mass\% WRHA or AR (curves 3 and 4) were shifted to lower temperatures and practically coincided. It indicates that the fillers used decreased the thermal stability of the initial copolymer to different extents. The weak influence of BRHA can be explained with the fact that its surface was carbonized which makes it more hydrophobic and more compatible with the initial copolymer. Vice versa, WRHA and AR, which were practically pure amorphous $\mathrm{SiO}_{2}$ have hydrophilic behavior and lower compatibility with the TFE-E copolymer. Besides, these fillers probably reduced copolymer thermal stability due to the fact that weak Brǿnsted acid centers exist on its surface stipulated by the surface $\mathrm{Si}-\mathrm{OH}$ groups. It is well known from the literature (Vlaev et al., 2008) that some solid acids like amorphous alumina, silica-alumina, clays, natural and synthetic zeolites, which have Brǿnsted or Lewis strong acid centers, can promote polymer chain cracking. In all these cases, the use of a catalyst reduces the energetic demand of the process and improves, from the economic point of view, the product distribution by increasing of yield of more volatile products and lowering the yield of sub products. An important feature of catalytic degradation is the need for proper contact between the polymer and the catalyst to minimize degradation residues.

Since the shapes of the TG curves shown in Figure 15 are different, it could be expected that the values of the activation energies $E$ and pre-exponential factor $A$ in Arrhenius equation characterizing the thermo oxidative degradation kinetics of the composites studied would be different. According to the TG-data, the oxidative thermal degradation of studied composites proceeded in two stages. The values of the kinetics parameters 
obtained for all the studied samples are presented in Table 5.

Table 5. Kinetic parameters of thermooxidative degradation of TFE-E and composites filled with 10 mass $\%$ BRHA, WRHA or AR (Atanassov et al., 2010)

\begin{tabular}{lllllll}
\hline Sample & $E, \mathrm{~kJ} / \mathrm{mol}$ & $A, \mathrm{~min}^{-1}$ & $\Delta S^{\ddagger}, \mathrm{J} / \mathrm{mol} \mathrm{K}$ & $E, \mathrm{~J} / \mathrm{mol}$ & $A, \mathrm{~min}^{-1}$ & $\Delta S^{\ddagger}, \mathrm{J} / \mathrm{mol} \mathrm{K}$ \\
\hline TFE-E & 181.9 & $1.67 \times 10^{12}$ & -60.4 & 96.6 & $1.38 \times 10^{6}$ & -177.6 \\
TFE-E + & 145.0 & $2.50 \times 10^{9}$ & -114.5 & 32.8 & 7.56 & -280.6 \\
$\begin{array}{l}10 \% \text { BRHA } \\
\text { TFE-E + }\end{array}$ & 163.2 & $7.79 \times 10^{10}$ & -85.9 & 55.9 & $9.55 \times 10^{2}$ & -238.1 \\
$\begin{array}{l}10 \% \text { WRHA } \\
\text { TFE-E + }\end{array}$ & 161.0 & $6.16 \times 10^{10}$ & -87.8 & 50.8 & $4.24 \times 10^{2}$ & -244.8 \\
$10 \%$ AR & & & & & & \\
\hline
\end{tabular}

As can be seen from Table 5, the highest values of $E$ and $A$ in both stages had the initial TFE-E copolymer and the lowest-the sample filled with 10 mass\% BRHA. Supposedly, it was due to the fact that this filler contains significant amount of porous amorphous carbon which burned under heating in air and facilitated the thermooxidative degradation of TFE-E copolymer. The close values of $E$ and $A$ in both stages for the samples filled with WRHA or AR were considered to be due to their similar nature. The fact that they were lower than these of the initial TFE-E copolymer showed that the surface acidic centers of these fillers play catalytic role in the thermooxidative degradation of TFE-E in air. The big differences between the values of the pre-exponential factor $A$ for both stages are very interesting. In the cases when the values of $A$ are between $10^{10}$ and $10^{12} \mathrm{~s}^{-1}$, the complex was probably highly restricted in rotation compared to the initial reagent (Atanassov et al., 2010). For the unimolecular case, the complex is expected to expand by size and, hence, interact more intensely with its neighbors. At values of $A$ less than $10^{6}$, the reagent is considered to be in equilibrium with the surface adsorption layer to become a product after passing through the activated complex. Such a situation can be observed during the second stage of decomposition since in this case significant amounts of monomers which are the final products of the degradation are adsorbed on filler surface. Since the frequency factor $A$ contains an entropy term $\left(\exp \Delta S^{ \pm} / \mathrm{R}\right)$, the values of $A$ reflect in a specific way on the change of the entropy $\Delta S^{ \pm}$for the formation of the activated complex from the reagents. The change in activation entropy $\Delta S^{\ddagger}$ reflects how near the system is own thermodynamic equilibrium. Low activation entropy means that the material has just passed through some kind of physical or chemical aging process, bringing it to a state near its own thermodynamic equilibrium. In this situation, the material shows little reactivity, increasing the time necessary to form the activated complex. On the other hand, when high activation entropy values are observed, the material is far from its own thermodynamic equilibrium. In this case, the reactivity is high and the system can react faster to produce the activated complex, and consequently short reaction times are observed. In particular, for example, the negative values of $\Delta S^{\ddagger}$ (Table 5) would indicate that the formation of the activated complex is connected with decrease of entropy i.e. the activated complex is "more organized" structure compared to the initial substance and such reactions are classified as "slow". Another parameter which can be calculated is lifetime of the studied samples. Lifetime estimations are very useful in the development or selection of polymers for different applications. For instance, the lifetime prediction of cables in nuclear power plants (NPPs) is based on the isothermal or non-isothermal simulation of their ageing and the well known Arrhenius equation. The cables are supposed to be used at NPPs without failure for $30-40$ years at temperatures up to $80^{\circ} \mathrm{C}$. At these temperatures, the plasticizers loss is due to their migration from bulk to surface and due to their evaporation. The cable becomes brittle and the glass transition temperature $T_{\mathrm{g}}$, increases (Beneš,et al., 2005; Paik et al., 2008).

Another consequence for the cable insulation materials degradation due to plasticizer loss is the development of micro voids and microscopic cavities. The lifetime is usually determined by accelerated aging, like air oven studies, which require long time periods. The apparent kinetic parameters calculated from this study have been used to arrive at the lifetime of the formulations.

The estimated lifetime or the time accelerating ageing $t_{\mathrm{f}}$ of a polymer to failure has been defined as the time when the mass loss reaches 5 mass \%. The life-times of the composites studied are presented in Table 6 . 
Table 6. Results for lifetime as a function of service temperature in air in the presence of 10 mass $\%$ different in nature fillers (Atanassov et al., 2010)

\begin{tabular}{|c|c|c|c|c|c|c|}
\hline \multirow{2}{*}{ Sample } & \multicolumn{6}{|c|}{ Lifetime, min } \\
\hline & $25^{\circ} \mathrm{C}$ & $50^{\circ} \mathrm{C}$ & $75^{\circ} \mathrm{C}$ & $100^{\circ} \mathrm{C}$ & $150^{\circ} \mathrm{C}$ & $200^{\circ} \mathrm{C}$ \\
\hline & \multicolumn{6}{|c|}{$\mathrm{I}^{\text {-st }}$ stage } \\
\hline TFE-E & $2.34 \times 10^{18}$ & $7.96 \times 10^{15}$ & $6.13 \times 10^{13}$ & $9.07 \times 10^{11}$ & $8.80 \times 10^{8}$ & $3.73 \times 10^{6}$ \\
\hline $\begin{array}{l}\text { TFE-E+10\% } \\
\text { BRHA }\end{array}$ & $5.33 \times 10^{14}$ & $5.74 \times 10^{12}$ & $1.19 \times 10^{11}$ & $4.13 \times 10^{9}$ & $1.64 \times 10^{7}$ & $2.10 \times 10^{5}$ \\
\hline $\begin{array}{l}\text { TFE-E+10\% } \\
\text { WRHA }\end{array}$ & $2.68 \times 10^{16}$ & $1.64 \times 10^{14}$ & $2.08 \times 10^{12}$ & $4.75 \times 10^{10}$ & $9.44 \times 10^{7}$ & $6.99 \times 10^{5}$ \\
\hline \multirow[t]{2}{*}{$\begin{array}{l}\text { TFE-E+10\% } \\
\text { AR }\end{array}$} & $1.40 \times 10^{16}$ & $9.13 \times 10^{13}$ & $1.23 \times 10^{12}$ & $2.95 \times 10^{10}$ & $6.39 \times 10^{7}$ & $5.05 \times 10^{5}$ \\
\hline & \multicolumn{6}{|c|}{$\mathrm{II}^{-\mathrm{nd}}$ stage } \\
\hline TFE-E & $3.19 \times 10^{9}$ & $1.56 \times 10^{8}$ & $1.18 \times 10^{7}$ & $1.26 \times 10^{6}$ & $3.16 \times 10^{4}$ & $1.73 \times 10^{3}$ \\
\hline $\begin{array}{l}\text { TFE-E+10\% } \\
\text { BRHA }\end{array}$ & $1.98 \times 10^{3}$ & $7.11 \times 10^{2}$ & $2.96 \times 10^{2}$ & $1.38 \times 10^{2}$ & $3.96 \times 10^{1}$ & $1.48 \times 10^{1}$ \\
\hline $\begin{array}{l}\text { TFE-E+10\% } \\
\text { WRHA }\end{array}$ & $3.38 \times 10^{5}$ & $5.90 \times 10^{4}$ & $1.32 \times 10^{4}$ & $3.62 \times 10^{3}$ & $4.30 \times 10^{2}$ & $8.02 \times 10^{1}$ \\
\hline $\begin{array}{l}\text { TFE-E }+10 \% \\
\text { AR }\end{array}$ & $9.72 \times 10^{4}$ & $1.99 \times 10^{4}$ & $5.11 \times 10^{3}$ & $1.57 \times 10^{3}$ & $2.27 \times 10^{2}$ & $4.93 \times 10^{1}$ \\
\hline
\end{tabular}

Table 6 shows that the lifetime is a parameter strongly depending on temperature and decreases exponentially with increase of temperature. Obviously, the initial TFE-E copolymer shows the highest values of the lifetime at all temperatures. Vice versa, the lowest lifetime had the sample containing 10 mass\% BRHA as a filler. As could be expected, the samples filled with 10 mass \% WRHA or AR have almost equal lifetimes since they had practically the same chemical composition and structure.

\subsection{Rice Husks Ash as Fillers in Rubbers}

RHA can also be used as filler in natural rubber, styrene butadiene rubber, nitrile butadiene rubber, butyl rubber etc. (Sun \& Gong, 2001; Chandrasekhar et al., 2003 Ismail \& Mega, 2001; Zurina et al., 2004; Arayapranee et al., 2005; Ismail, Mega, \& Khalil, 2001; Ismail, Nizam, \& Khalil, 2001; Chung, Ismail \& Chung, 1999). Especially in epoxidized natural rubber, the addition of WRHA can increase the tensile strength, tear strength and hardiness of the rubber. As WRHA is predominantly silica, it responds effectively to silane coupling agents in improving the rubber compounds properties. WRHA modified by silane-coupling agents not only can effectively improve epoxidized natural rubber's mechanical properties, such as tensile and tear strength, but also can improve its cure characteristics. The cure characteristics of WRHA filled vulcanizates show a close resemblance to those of carbon black. This can be attributed to the similarities of filler-related parameters such as surface area, surface reactivity, particle size, and metal oxide content. Generally, WRHA is not as good as fumed silica and carbon black, especially in terms of tensile strength and tear strength, but it can replace or partially replace fumed silica and carbon black on some occasions (Ishak \& Baker, 1995; Ismail et al., 1998, Ismail \& Chung, 1998). In addition, WRHA can sometimes be combined with other fillers, especially with reinforcing blacks. The properties obtained are linear functions of the amount of the particular filler present in the blend. BRHA has a lower silica content, typically about 54 mass $\%$ and a substantial carbon content of about 44 mass\%. It can be also used as a filler for rubber, but the effect is not as good as can be obtained with WRHA (Ismail \& Chung, 1998; Da Costa et al., 2000).

\section{Conclusions}

The reduction of environmental pollution and the utilization of agricultural and processing waste are prerequisites for a successful economy and sustainable development. As a by-product of the paddy milling industry and a waste product from agriculture, rice husks can be regarded as a substantial source of raw biomass material which holds a significant potential for obtaining value-added silicon composite products. For this reason, the use of raw rice husks and the products of their thermal degradation are currently the object of intense studies.

The application of the method of controlled thermal treatment of raw rice husks results in obtaining first-rate starting materials for the preparation of advanced high-quality ceramic powders, such as silicon carbide, silicon nitride and magnesium silicide, which can be used in high temperature material engineering. Furthermore, small amounts of pure silica powder can be employed in the production of high purity elemental silicon needed for 
electronics, adsorbents, catalyst support, thermal insulators and as a thixotropic agent. Other recent applications of rice husk ashes include fillers of rubbers, plastics and cement. They may be a lucrative replacement of the relatively expensive condensed silica fume. Laboratory results lead to the conclusion that, after vigorous grounding and mixing, cheap raw rice husks and the products of their thermal degradation (BRHA and WRHA) can be used successfully as fillers for polypropylene and tetrafluoroethylene-ethylene copolymer, thus replacing the costly synthetic additive Aerosol in the preparation of a range of polymer composites. RHA-polymer composites can lead to the development of innovative hybrid organic-inorganic materials with specific properties.

Finally, besides giving rise to the formation of cheap and valuable products, the utilization of such an abundant agricultural waste as rice husks, will reduce pollution and thus have a positive effect on the environment.

\section{Acknowledgements}

The authors would like to express their gratitude to Operating Programme Human Resources Development; Grant agreement: BG051PO001/3.3-05-001 "Science and Business" Funded by: EC, European Social Fund for their financial support.

\section{References}

Adam, F., \& Chua, J. H. (2004). The adsorption of palmytic acid on rice husk ash chemically modified with $\mathrm{Al}(\mathrm{III})$ ion using the sol-gel technique. J. Coll. Int. Sci., 280, 55-61. http://dx.doi.org/10.1016/j.jcis.2004.07.006

Acharya, H. N., Dutta, S. K., \& Banerjee, H. D. (1980). Production of magnesium silicide and silane from rice husk ash. Sol. Energy Mater., 3, 441-443. http://dx.doi.org/10.1016/0165-1633(80)90032-5

Andreas, M., \& Hartmut, W. (2001). Injection Molding of Natural Fiber Reinforced Thermoplastics. Kunststoffe Plast Europe, 91, 25-27.

Amorim, J. J., Eliziario, S. A., Gouveia, D. ., Simoes, A. S. M. J., Santos, C. O., Conceicao, M. M., ... Trindade, M. F. S. (2004). Thermal analysis of the rice and by-products. J. Thermal Anal. Calorim., 75, 393-399. http://dx.doi.org/10.1023/B:JTAN.0000027125.77040.43

Arayapranee, W., Naranong, N., \& Rempel, G. L. (2005). Application of rice husk ash as fillers in the natural rubber industry. J. Appl. Polymer Sci., 98, 34-41. http://dx.doi.org/10.1002/app.21004

Armesto, L., Bahillo, A., Veijionen, K., Cabanillas, A., \& Otero, J. (2002). Combustion behavior of rice husk in a bubbling fluidized bed. Biomass and Bioenergy, 23, 171-179. http://dx.doi.org/10.1016/S09619534(02)00046-6

Asavapisit, S., \& Ruengrit, N. (2005). The role of RHA-blended cement in stabilizing metal-containing wastes. Cement and Concrete Composites, 27, 782-787. http://dx.doi.org/10.1016/j.cemconcomp.2005.03.003

Atanassov, A., Genieva, S., \& Vlaev, L. (2010). Study of the thermooxidative degradation kinetics of tetrafluoroethylene-ethylene copolymer filled with rice husks ash. Polym.-Plast. Technol. Eng., 49, 541-554. http://dx.doi.org/10.1080/03602550903532224

Babel, S., \& Kurniawan, T. A. (2003). Low cost adsorbents for heavy metals uptake from contaminated water: a review. J. Hazardous Mater., B97, 219-243. http://dx.doi.org/10.1016/S0304-3894(02)00263-7

Bailey, S. E., Olin, T. J., Bricka, R. M., \& Adrian, D. D. (1999). A review of potentially low-cost sorbents for heavy metals. Water Res., 33, 2469-2479. http://dx.doi.org/10.1016/S0043-1354(98)00475-8

Basu, P. K., King, C. J., \& Lynn, S. (1973). Manufacture of silicon tetrachloride from rice hulls. AIChE J, 19, 439-445. http://dx.doi.org/10.1002/aic.690190304

Bhattacharya, S. C., Shah, N., \& Alikhani, Z. (1984). Some aspects of fluidized bed combustion of paddy husk. Applied Energy, 16, 307-316. http://dx.doi.org/10.1016/0306-2619(84)90005-9

Beneš, M., Plaček, V., Matuschek, G., Kettrup, A. A., Györyová, K., Emmerich, W. D., \& Balek, V. (2005). Lifetime simulation and thermal characterization of PVC cable insulation materials. J. Therm. Anal. Calorim., 83, 761-768.

Carniti, P., \& Gervasini, A. (2001). Thermogravimetric study of the kinetics of degradation of polypropylene with solid catalysts. Thermochim. Acta, 379, 51-58. http://dx.doi.org/10.1016/S0040-6031(01)00601-3

Chakraverty, A., Mishra, P., \& Banerjee, H. D. (1985). Investigation of thermal decomposition of rice husk. Thermochim. Acta, 94, 257-275. http://dx.doi.org/10.1016/0040-6031(85)85270-9

Chandrasekhar, S., Satyanarayana, K. G., Pramada, P. N., Raghavan, P., \& Gupta,T. N. (2003). Processing, 
properties and applications of reactive silica from rice husk-an overview. J. Mater. Sci., 38, 3159-3168. http://dx.doi.org/10.1023/A:1025157114800

Chandrasekhar, S., Pramada, P. N., \& Praveen, L. (2005). Effect of organic acid treatment on the properties of rice husk silica. J. Mater. Sci., 40, 6535-6544. http://dx.doi.org/10.1007/s10853-005-1816-z

Chang, F. W., Kuo, W. Y., \& Yang, H. C. (2005). Preparation of $\mathrm{Cr}_{2} \mathrm{O}_{3}$-promoted copper catalysts on rice husk ash by incipient wetness impregnation. Appl. Catal. A: General, 288, 53-61. http://dx.doi.org/10.1016/j.apcata.2005.04.046

Chang, F. W., Yang, H. C., Roselin, L. S., \& Kuo, W. Y. (2006). Ethanol dehydrogenation over copper catalysts on rice husk ash prepared by ion exchange. Appl. Catal. A: General, 304, 30-39. http://dx.doi.org/10.1016/j.apcata.2006.02.017

Chareonpanich, M., Namto, T., Kongkachuichay, P., \& Limtrakul, J. (2004). Synthesis of ZSM-5 zeolite from lignite fly ash and rice husk ash. Fuel Proc. Technol., 85, 1623-1634. http://dx.doi.org/10.1016/j.fuproc.2003.10.026

Chaudhary, D. S., Jollands, M. C., \& Cser, F. (2002). Understanding rice hull ash as fillers in polymers: A review. Silicon Chem., 1, 281-289. http://dx.doi.org/10.1023/B:SILC.0000018361.66866.80

Chaudhary, D. S., Jollands, M. C., \& Cser, F. (2004). Recycling rice husk ash: A filler material for polymeric composites. Adv. Polym.Technol., 23, 147-155. http://dx.doi.org/10.1002/adv.20000

Chaudhary, D. S., \& Jollands, M. C. (2004). Characterization of rice hull ash. J. Appl. Polymer Sci., 93, 1-8. http://dx.doi.org/10.1002/app.20217

Choi, N. W., Mori, I., \& Ohama, Y. (2006). Development of rice husk-plastics composites for building materials. Waste Manag., 26, 189-194. http://dx.doi.org/10.1016/j.wasman.2005.05.008

Chuah, T. G., Jumasiah, A., Aznu, I., Katayon, S., \& Thomas Choong S. Y. (2005). Rice husks as a potentially low-cost biosorbent for heavy metal and dye removal: an overview. Desalination, 175, 305-316. http://dx.doi.org/10.1016/j.desal.2004.10.014

Crini, G. (2006). Non-conventional low-cost adsorbents for dye removal: A review. Bioresource Technol., 97, 1061-1085. http://dx.doi.org/10.1016/j.biortech.2005.05.001

Chakraverty, A., Mishra, P., \& Banerjee, H. D. (1985). Investigation of thermal decomposition of rice husk. Thermochim. Acta, 94, 257-275. http://dx.doi.org/10.1016/0040-6031(85)85270-9

Da Costa, H. M., Visconte, L. L. Y., Nunes, R. C. R., \& Furtado, C. R. G. (2000). The effect of couplung agent and chemical treatment on rice husk ash-filled natural rubber composites. J. Appl. Polym. Sci., 76, 10191027. http://dx.doi.org/10.1002/(SICI)1097-4628(20000516)76:7<1019::AID-APP5>3.0.CO;2-\#

Daifullah, A. A. M., Girgis, B. S., \& Gad, H. M. H. (2003). Utilization of agro-residues (rice husk) in small waste water treatment plants. Mater. Letters, 57, 1723-1731. http://dx.doi.org/10.1016/S0167577X(02)01058-3

Della, V. P., Kuhn, I., \& Hotza, D. (2002). Rice husk ash as an alternative source for active silica production. Mater. Letters, 57, 818-821. http://dx.doi.org/10.1016/S0167-577X(02)00879-0

Estevez, M., Vargas, S., Castano, V. M., \& Rodriguez, R. (2009). Silica nano-particles produced by worms through a bio-digestion process of rice husk. J. Non-Crystalline Solids, 355, 844-850. http://dx.doi.org/10.1016/j.jnoncrysol.2009.04.011

Fang, M., Yang, L., Chen, G., Shi, Z., Luo, Z., \& Cen, K. (2004). Experimental study on rice husk combustion in a circulating fluidized bed. Fuel Proc. Technol., 85, 1273-1282. http://dx.doi.org/10.1016/j.fuproc.2003.08.002

Feng, J., \& Chan, C. M. (2003). Effects of strain and temperature on the electrical properties of carbon blackfilled alternating copolymer of ethylene-tetrafluoroethylene composites. Polym. Eng. Sci., 43, 1064-1070. http://dx.doi.org/10.1002/pen.10090

Fuad, M. Y. A., Yaakob, I., Ishak, Z. A. M., \& Omar, A. K. M. (1993). Density measurement of rice husk ash filler particles in polypropylene composites. Polymer Testing, 12, 107-112. http://dx.doi.org/10.1016/01429418(93)90033-L

Fuad, M. Y. A., Mustafah, J., \& Mansor, M. S. (1995). Thermal properties of polypropylene/rice husk ash composites. Polymer Int., 38, 33-43. http://dx.doi.org/10.1002/pi.1995.210380104 
Fuad, M. Y. A., Zaini, M. J., Ishak, Z. A. M., \& Omar, A. K. M. (1994). Rice husk ash (RHA)-based silica as a filler in polypropylene composite: Effect of peroxide-containing silane on the rheological behavior. $J$. Elastomers and Plastics, 26, 252-264. http://dx.doi.org/10.1177/009524439402600304

Fuad, M. Y. A., Zaini, M. J., Jamaludin, M. J., Ishak, Z. A. M., \& Omar, A. K. M. (1994). Determination of filler content in rice husk ash and wood-based composites by thermogravimetric analysis. J. Appl. Polymer Sci., 51, 1875-1882. http://dx.doi.org/10.1002/app.1994.070511104

Fuad, M. Y. A., Jamaludin, M., Ishak, Z. A. M., \& Omar, A. K .M. (1993). Rice husk ash as filler in polypropylene: Preliminary study. Int. J. Polym. Mater., 19, 75-92. http://dx.doi.org/10.1080/00914039308012019

Fuad, M. Y. A., Ishak, Z. A. M., \& Omar, A. K. M. (1994). Rice husk ash as a filler in polypropylene: effect of max and silane coupling agents. Plastics, Rubber and Composites Processing and Applications, 21, 225235 .

Fuad, M. Y. A., Ismail, Z., Ishak, Z. A. M., \& Omar, A. K. M. (1995). Application of rice husk ash as fillers in polypropylene: Effect of titanate, zirconate and silane coupling agents. Eur. Polym. J., 31, 885-893. http://dx.doi.org/10.1016/0014-3057(95)00041-0

Fuad, M. Y. A. (1994). Application of rice husks ashes as fillers in polypropylene composites. Ph.D. thesis, University Sains Malaysia.

Ganesh, A., Grover, P. D., \& Ramachandralyer, P. V. (1992). Combustion and gasification characteristics of rice husk. Fuel, 71, 889-894. http://dx.doi.org/10.1016/0016-2361(92)90238-J

Garbuglio, C., Modena, M., Valera, M., \& Ragazini, M. (1974). Properties of a new thermoplastic fluorinated polymer. Eur. Polym. J., 10, 91-95. http://dx.doi.org/10.1016/0014-3057(74)90056-1

Genieva S. D., Turmanova, S. Ch., Dimitrova, A. S., \& Vlaev, L. T. (2008). Characterization of rice husks and the products of its thermal degradation in air or nitrogen atmosphere. J. Thermal Anal. Calorim., 93, 387396. http://dx.doi.org/10.1007/s10973-007-8429-5

George, J., Bhagawan, S. S., \& Thomas, S. (1998). Effects of environment on the properties of low-density polyethylene composites reinforced with pineapple-leaf fibre. Comp. Sci. Technol., 58, 1471-1485. http://dx.doi.org/10.1016/S0266-3538(97)00161-9

Ghosh, T. B., Nandi, K. C., Acharya, H. N., \& Mukherjee, D. (1991). XPS studies of magnesium silicide obtained from rice husk. Mater. Lett., 11, 6-9. http://dx.doi.org/10.1016/0167-577X(91)90179-A

Gokhal, K. V. G. K., Dalai, A. K., \& Rao, M. S. (1986). Thermal characteristics of synthetic sodium zeolites prepared with silica from rice-husk ash. J. Term. Anal., 31, 33-39. http://dx.doi.org/10.1007/BF01913884

Govindarao, V. M. H. (1980). Utilization of rice husk: a preliminary analysis. J. Sci. Ind. Res., 39, 495-515.

Gregg, S. J, \& Sing, K. S. W. (1982). Adsorption, surface area and porosity. (2nd ed.). London: Academic Press.

Hamad, M. A., \& Khattab, I. A. (1981). Effect of the combustion process on the structure of rice hull silica. Thermochim. Acta, 48, 343-349. http://dx.doi.org/10.1016/0040-6031(81)80255-9

Han, H. W., Huang, C. Y., \& Liu, H. S. (1999). Formation of gehlenite $\left(\mathrm{Ca}_{2} \mathrm{Al}_{2} \mathrm{SiO}_{7}\right)$ by carbothermal reduction of carbonized rice hulls. J. Ceram. Soc. Jpn., 107, 1115-1120. http://dx.doi.org/10.2109/jcersj.107.1115

Huang, S., Jing, S., Wang, J., Wang, Z., \& Jin, Y. (2001). Silica white obtained from rice husk in a fluidized bed. Power Technology, 117, 232-238. http://dx.doi.org/10.1016/S0032-5910(00)00372-7

Hunt, L. P., Dismukes, J. P., Amick, J. A., Schei, A., \& Larsen, K. K. (1984). Rice husk as a raw material from producing silicon. J. Electrochem. Soc., 131, 1683-1686. http://dx.doi.org/10.1149/1.2115937

Hummel, D. O., \& Scholl F. (1968). Atlas den Kunststoff-analyze, Band 1. Munchen: Carl Hanser Verlag, pp 131.

Ishak, Z. A. M., \& Baker, A. A. (1995). An investigation on the potential of rice husk ash as fillers for epoxidized natural rubber (ENR). Eur. Polymer J., 31, 259-269. http://dx.doi.org/10.1016/0014-3057(94)00156-1

Ismail, H., \& Mega, L. (2001). The effects of a compatibilizer and a silane-coupling agent on the mechanical properties of polypropylene/natural rubber blend. Polym. Plast. Technol. Eng., 40(4), 463-478. http://dx.doi.org/10.1081/PPT-100002070

Ismail, H., Hong, H. B., Ping, C. Y., \& Khalil, H. P. S. (2003). Polypropylene/Silica/Rice husk ash hybrid composites: A study on the mechanical, water adsorption and morphological properties. J. Thermoplastic 
Composite Mater., 16, 121-137. http://dx.doi.org/10.1177/0892705703016002871

Ismail, H., Mohamad, Z., \& Bakar, A. A. (2003). A comparative study of processing, mechanical properties, thermo-oxidativeaging, water adsorption, and morphology of rice husk powder and silica fillers in polystyrene/styrene butadiene rubber blends. Polymer-Plastics Technol. Eng., 42(1), 81-103. http://dx.doi.org/10.1081/PPT-120016337

Ismail, H., \& Chung, F. L. (1999). The effect of partial replacement of silica by white rice husk ash in natural rubber composites. Int. J. Polymeric Mater., 43, 301-312. http://dx.doi.org/10.1080/00914039908009692

Ismail, H., Mega, L., \& Khalil, H. P. S. (2001). Effect of a silane coupling agent on the properties of white rice husk ash-polypropylene/natural rubber composites. Polymer Int., 50, 606-611. http://dx.doi.org/10.1002/pi.673

Ismail, H., Nizam, J. M., \& Khalil, H. P. S. (2001). The effect of a compatibilizer on the mechanical properties and mass swell of white rice husk ash filled natural rubber/linear low density polyethylene blends. Polymer Testing, 20, 125-133. http://dx.doi.org/10.1016/S0142-9418(00)00013-1

Ismail, H., Hong, H. B., Ping, C. Y., \& Abdul Khalil, H. P. S. (2003). Polypropylene/Silica/Rice Husk Ash Hybrid Composites: A Study on the Mechanical, Water Absorption and Morphological Properties. J. Thermoplastic Comp. Mater., 16, 121-137. http://dx.doi.org/10.1177/0892705703016002871

Ismail, H., Ishaku, U. S., Arinab, A. R., \& Ishak, Z. A. M. (1998). Epoxidized natural rubbercomposites: Effect of vulcanization systems and fillers. Polym.-Plast. Technol. Eng., 37, 469-474. http://dx.doi.org/10.1080/03602559808001374

Ismail, H., \& Chung, F. L. (1998). Partial replacement of silica by white rice husk ash in natural rubber composites: the effect of bonding agents. Iran. Polym. J. (Engl. Ed.), 7, 255-261.

Jacob, M., Varughesee, K. T., \& Thomas, S. (2005). Water sorption studies of hybrid biofiber-reinfotced natural rubber biocomposites. Biomacromolecules, 6, 2969-2979. http://dx.doi.org/10.1021/bm050278p

James, J. M., \& Rao, S. (1986). Silica from rice husk thorough thermal decomposition. Thermochim. Acta, 97, 329-336. http://dx.doi.org/10.1016/0040-6031(86)87035-6

Janvijitsakul, K., \& Kuprianov, V. I. (2008). Major gaseous and PAN emissions from fluidized-bed combustor firing rice husk with high combustion efficiency. Fuel Proces. Tech., 89, 777-787. http://dx.doi.org/10.1016/j.fuproc.2008.01.013

Jauberthie, R., Rendell, F., Tamba, S. E., \& Cisse, I. K. (2003). Properties of cement-rice husk mixture. Constr. Build. Mater, 17, 239-243. http://dx.doi.org/10.1016/S0950-0618(03)00005-9

Jiang, H., Zhu, X., Guo, Q., \& Zhu, Q. (2003). Gasification of rice husk in a fluidized-bed gasifier without inert additives. Ind. Eng. Chem. Res., 42, 5745-5750. http://dx.doi.org/10.1021/ie0304659

Kalapathy, U., Proctor, A., \& Shultz, J. (2000). Production and properties of flexible sodium silicate films from rice hull ash silica. Bioresource Technol., 72, 99-106. http://dx.doi.org/10.1016/S0960-8524(99)00112-1

Kalapathy, U., Proctor, A., \& Shultz, J. (2000). A simple method for production of pure silica from rice hull ash. Bioresource Technol., 73, 257-262. http://dx.doi.org/10.1016/S0960-8524(99)00127-3

Kalapathy, U., Proctor, A., \& Shultz, J. (2002). An improved method for production of silica from rice husk ash. Bioresource Technol., 85, 285-289. http://dx.doi.org/10.1016/S0960-8524(02)00116-5

Kalderis, D., Bethanis, S., Paraskeva, P., \& Diamadopoulos, E. (2008). Production of activated carbon from baggase and rice husk by single-stage chemical activation method at low retention times. Bioresource Technol., 99, 6809-6816. http://dx.doi.org/10.1016/j.biortech.2008.01.041

Kaushik, V., Sharma, H. K., Prasad, K., \& Bera, B. M., (2001). Utilization of husk ash from rice milling industry: a review. J. Ind. Poll. Control, 17, 201-205.

Kennedy, L. J., Vijaya, J. J., \& Sekaran, G. (2004). Effect of two-stage process on the preparation and characterization of porous carbon composite from rice husk by phosphoric acid activation. Ind. Eng. Chem. Res., 43, 1832-1838. http://dx.doi.org/10.1021/ie034093f

Kim, H. S., Yang, H. S., Kim, H. J., \& Park, H. J. (2004). Thermogravimetric analysis of rice husk flour filled thermoplastic polymer composites. J. Thermal Anal. Cal., 76, 395-404. http://dx.doi.org/10.1023/B:JTAN.0000028020.02657.9b

Krishnarao, R. V., Mahajan, Y. R., \& Kumar, T. J. (1998). Conversion of raw rice husk to SiC by pyrolysis in 
nitrogen atmosphere. J. Eur. Ceramic Soc., 18, 147-152. http://dx.doi.org/10.1016/S0955-2219(97)00093-9

Kumar, B., \& Godkhindi, M. M. (1996). Studies on the formation of $\mathrm{SiC}, \mathrm{Si}_{3} \mathrm{~N}_{4}$, and $\mathrm{Si}_{2} \mathrm{~N}_{2} \mathrm{O}$ during pyrolysis of rice husks. J. Mater. Sci. Letters, 15, 403-405.

Kurama, S., \& Kurama, H. (2008). The reaction kinetics of rice husk based cordierite ceramics. Ceramics International, 34, 269-272. http://dx.doi.org/10.1016/j.ceramint.2006.09.017

Lakshmi, U. R., Srivastava, V. C., Mall, I. D., \& Lataye, D. H. (2009). Rice husk ash an effective adsorbent: Evaluationof adsorptive characteristics for Indigo Carmine dye. J. Environmental Management, 90, 710720. http://dx.doi.org/10.1016/j.jenvman.2008.01.002

Li, X., Tabil, L. G., \& Panigrahi, S. (2007). Chemical treatments of natural fiber for use in natural fiberreinforced composites: A review. J. Polymer Environ., 15, 25-33. http://dx.doi.org/10.1007/s10924-0060042-3

Liou, T. H. (2004). Evolution of chemistry and morphology during the carbonization and combustion of rice husk. Carbon, 42, 785-794. http://dx.doi.org/10.1016/j.carbon.2004.01.050

Liou, T. H. (2004). Preparation and characterization of nano-structured silica from rice husk. Mater. Sci. Eng., A364, 313-323. http://dx.doi.org/10.1016/j.msea.2003.08.045

Liu, Z., Song, Y., Shangguan, Y., \& Zheng, Q. (2007). Conductive behaviour of composites composed of carbon black-filled ethylene-tetrafluoroethylene copolymer. J. Mater. Sci., 42, 2903-2906. http://dx.doi.org/10.1007/s10853-007-1603-0

Mansaray, K. G., Ghaly, A. E., Al-Taweel, A. M., Hamdullahpur, F., \& Ugursal, V. I. (1999). Air gasification of rice husk in a dual distributor type fluidized bed gasifier. Biomass and Bioenergy, 17, 315-332. http://dx.doi.org/10.1016/S0961-9534(99)00046-X

Mansaray, K. G., \& Ghaly, A. E. (1999). Determination of kinetic parameters of rice husk in oxygen using thermogravimetric analysis. Biomass and Bioenergy, 17, 19-31. http://dx.doi.org/10.1016/S09619534(99)00022-7

Mansaray, K. G., \& Ghaly, A. E. (1999). Thermal degradation of rice husks in oxygen atmosphere. Energy Sources, 21, 453-466. http://dx.doi.org/10.1080/00908319950014759

Mishra, S., \& Verma, J. (2006). Effect of compitibilizers on water absorption kinetics of polypropylene/wood flour foamed composites. J. Appl. Polymer Sci., 101, 2530-2537. http://dx.doi.org/10.1002/app.23916

Mishra, P., Chakraverty, A., \& Banerjee, H. D. L. (1986). Studies on physical and thermal properties of rice husk related to its industrial application. Mater. Sci., 21, 2129-2132. http://dx.doi.org/10.1007/BF00547958

Mohanty, K., Naidu, J. T., Meikap, B. C., \& Biswas, M. N. (2006). Removal of crystal violet from wastewater by activated carbons prepared from rice husk. Ind. Eng. Chem. Res., 45, 5165-5171. http://dx.doi.org/10.1021/ie060257r

Moreland, J. E. (1979). The first decade of inorganic and organic surface modification, In: Society of the plastics industry, reinforced plastics/composites industrie, proceedings of the 34th Annual Conference, Jan.30-Feb 2 1979; Society of Plastics Industry, New York, Section 14-A.

Muthadhi, A., Anitha, R., \& Kothandaraman, S. (2007). Rice husk ash-Properties and its use: A review. IE(I) Journal-CV, 88, 50-56.

Nandi, K. C., Mukherjee, D., Biswas, A. K., \& Acharia, H. N. A. (1991). A novel and inexpensive method of production of silanes from rice husk and theirgas chromatographic analyses. Sol. Energy mater, 22, 161164. http://dx.doi.org/10.1016/0165-1633(91)90014-C

Nassar, M. A. (2007). Composites from sawdust-rice husk fibers. Polymer-Plastics Technology and Engineering, 46, 441-446. http://dx.doi.org/10.1080/03602550600887277

Natarajan, E., Nordin, A., \& Rao, A. N. (1998). Overview of combustion and gasification of rice husk in fluidized bed reactor. Biomass and Bioenergy, 14(5-6), 533-546. http://dx.doi.org/10.1016/S09619534(97)10060-5

Oh, G. H., \& Park, C. R. (2002). Preparation and characteristics of rice-straw-based porous carbon with high adsorption capacity. Fuel, 81, 327-336. http://dx.doi.org/10.1016/S0016-2361(01)00171-5

Paik, P., \& Kar, K. K. (2008). Kinetics of thermal degradation and estimation of lifetime for polypropylene particles: Effects of particle size. Polym. Degrad. Stab., 93, 24-35. 
http://dx.doi.org/10.1016/j.polymdegradstab.2007.11.001

Panthapulakkal, S., Law, S., \& Sain, M. (2005). Enhancement of process ability of rice husk filled high-density polyethylene composite profiles. J. Thermoplastic Comp. Mater., 18, 445-458. http://dx.doi.org/10.1177/0892705705054398

Petro, F., Anthony, E. J., Disea, D. L., \& Friedrich, F. D. (1987). Combustion trials of rice husk in a pilot-scale fluidized bed. Proceeding of the 9th International Conference on Fluidized Bed Combustion, 2, 1123-1127.

Prachayawarakorn, J., \& Yeambunying, N. (2005). Effect of recycling on properties of rice husk-filledpolypropylene. J. Sci. Technol., 27, 343-352.

Premalal, H. G. B., Ismail, H., \& Baharin, A. (2002). Comparison of the mechanical properties of rice husk powder filled polypropylene composites with talc filled polypropylene composites. Polymer Testing, 21, 833-839. http://dx.doi.org/10.1016/S0142-9418(02)00018-1

Premalal, H. G. B., Ismail, H., \& Baharin, A. (2003). Effect of processing time on the tensile, morphological and thermal properties of rice husk powder-filled polypropylene composites. Polymer-Plastics Technology Eng., 42, 827-851. http://dx.doi.org/10.1081/PPT-120024998

Pukanszky, B. (1995). Chapter 13 in Polypropylene structure, blends and composites, Ed. J. Karger-Kocsis, London: Chapman \&Hall.

Qiaoqun, S., Huilin, L., Wentie, L., Yurong, H., Lidan, Y., \& Gidaspow, D. (2005). Simulation and experiment of segregating/mixing of rice husk-sand mixture in a bubbling fluidized bed. Fuel, 84, 1739-1748. http://dx.doi.org/10.1016/j.fuel.2004.09.026

Rahnman, I. A., \& Saleh, M. I. (1995). Formation of $\beta$-sialon in the carbothermal reduction of digested rice husks. Lett., 23, 157-161.

Razavi-Nouri, M., Dogouri, F. J., Oromiehie, A., \& Langroudi, A. E. (2006). Mechanical properties and water absorption behaviour of chopped rice husk filled polypropylene composites. Iranian Polymer J., 15, $757-$ 766.

Real, C., Alcala, M. D., \& Criado, J. M. (2004). Synthesis of silicon nitride from carbothermal reduction of rice husk by the constant-rate-thermal-analysis (CRTA) method. J. Am. Ceram. Soc., 87, 75-78. http://dx.doi.org/10.1111/j.1551-2916.2004.00075.x

Renu, P., Radhika, T., \& Sugunan, S. (2008). Characterization and catalytic activity of vanadia supported on rice husk silica promoted samaria. Natural fiber polymer composites. Catalysis Commun., 9, 584-589. http://dx.doi.org/10.1016/j.catcom.2007.02.024

Rodriguez-Lugo, V., Ribio, E., Gomez, I., Torres-Martinez, L., \& Castano, V. M. (2002). Synthesis of silicon carbide from rice husk. Int. J. Environ. Pollution, 18, 378-387. http://dx.doi.org/10.1504/IJEP.2002.003734

Rozainee, M. (2007). Production of amorphous silica from rice husk in fluidized bed system. Faculty of Chemical Engineering and Natural Resource Engineering, Universiti Teknologi Malaisia.

Rozainee, M., Ngo, S. P., Salema, A. A., Tan, K. G., Ariffin, M., \& Zainura, Z. N. (2008). Effect of fluidizing velocity on the combustion of rice husk in a bench-scale fluidized bed combustor for the production of amorphous rice husk ash. Bioresource Technology, 99, 713. http://dx.doi.org/10.1016/j.biortech.2007.01.049

Ruvollo Filho, A., \& Curti, P. S. (2006). Chemical kinetic model and thermodynamic compensation effect of alkaline hydrolysis of waste poly(ethylene terephthalate) in nonaqueous ethylene glycol. Ind. Eng. Chem. Res., 45, 7985-7996. http://dx.doi.org/10.1021/ie060528y

Saheb, D. N., \& Jog, J. P. (1999). Understanding rice hull ash as fillers in polymers: A review. Advance in Polymer Technology, 18 (4), 351-363. http://dx.doi.org/10.1002/(SICI)1098-2329(199924)18:4<351::AIDADV6>3.0.CO;2-X

Sain, M., Law S., Suhara, F. \& Boullinox, A. (2003) Stiffness correlation of natural fiber filled polypropylene composite In: Proceedings of Wood fiber polymers Composite Symposium, 25-27 March 2003, France.

Sekar, N., \& Virutha Giri, T. (2005). Preparation of sodium silicate from waste rice husk. Chem. Eng. World, 40, 81-85.

Seo, E. S. M., Andreoli, M., \& Chiba, R. (2003). Silicon tetrachloride production by chlorination method using rice husk as raw material. J. Mater. Proc. Technol., 141, 351-356. http://dx.doi.org/10.1016/S0924- 


\section{6(03)00287-5}

Sharma, P., Kaur, R., Baskar, C., \& Chung, W. J. (2010). Removal of methylene blue from aqueous waste using rice husk and rice husk ash. Desalination, 259, 249-257. http://dx.doi.org/10.1016/j.desal.2010.03.044

Sharma, A., \& Rao, T. R. (1999). Kinetics of pyrolysis of rice husk. Bioresource Technol., 67, 53-59. http://dx.doi.org/10.1016/S0960-8524(99)00073-5

Shimokawa, K., Sekiguchi, I., Suzuki, Y., \& Ueda, Y. (1992). Synthesis of Si-O-C fibers from rice husk carbideexplanation of formation condition. J. Ceram. Soc. Jpn., (Int. Ed.) 100, 1111-1119.

Singh N. B., Singh, N., Rai, S., \& Singh, N. (2001). Hydration of rice husk ash blended Portland cement. Indian J. Eng. Mater. Sci., 8, 235-238.

Siriwardena, S., Ismail, H., \& Ishiaku, U. S. (2001). A comparison of white-rice husk ash and silica as a fillers of ethylene-propylene-diene terpolymer vulcanizates. Polymer Int., 50, 707-713. http://dx.doi.org/10.1002/pi.691

Siriwardena, S., Ismail, H., \& Ishiaku, U. S. (2001). White rice husk ash filled ethylene-propylene-diene terpolymer/polypropylene blends: Effect of dynamic vulcanization and filler loading. Polymer Plastics Technology and Engineering, 40, 519-548. http://dx.doi.org/10.1081/PPT-100002074

Siriwardena, S., Ismail, H., \& Ishiaku, U. S. (2002). Water adsorption behaviour and its effect on tensile properties of ethylene-propylene-diene-terpolymer/polypropylene/filler ternary composites: A preliminary study. Polym.-Plast. Technol. Eng., 41(3), 419-433. http://dx.doi.org/10.1081/PPT-120004360

Siriwardena, S., Ismail, H., Ishiaku, U. S., \& Perera, M. C. S. (2002). Mechancal and morphological properties of white rice husk ash filled polypropylene/ethylene-propylene-diene terpolymer thermoplastic elastomer composites. J. Appl. Polymer Sci., 85, 438-453. http://dx.doi.org/10.1002/app.10713

Siriwardena, S., Ismail, H., \& Ishiaku, U. S. (2003). A comparison of the mechanical properties and water adsorption behaviour of white rice husk and silica filled polypropylene composites. J. Reinforced Plastics and Composites, 22, 1645-1666. http://dx.doi.org/10.1177/073168403027619

Sujirote, K., \& Leangsuwan, P. (2003). Silicon carbide formation from pretreated rice husks. J. Mater. Sci., 38, 4739-4744. http://dx.doi.org/10.1023/A:1027475018767

Sun, L., \& Gong, K. (2001). Silicon-based materials from rice husks and their applications. Ind. Eng. Chem. Res., 40, 5861-5877. http://dx.doi.org/10.1021/ie010284b

Tanev, P., \& Vlaev, L. (1993). An attempt at a more precise evaluation of the approach to mesopore size distribution calculations depending on the degree of pore blocking. J. Coll. Int. Sci., 160, 110-116. http://dx.doi.org/10.1006/jcis.1993.1374

Toro, P., Quijada, R., Murillo, O., \& Yazdani-Pedram, M. (2005). Study of the morphology and mechanical properties of polypropylene composites with silica or rice-husk. Polymer International, 54, 730-734. http://dx.doi.org/10.1002/pi.1740

Tsai, M. T., \& Chang, F.W. (2000). Characterization of rice husk ash-supported nickel catalysts prepared by ion exchange. Appl. Catal. A: General, 203, 15-22. http://dx.doi.org/10.1016/S0926-860X(00)00464-6

Turmanova, S. Ch., Genieva, S. D., Dimitrova, A. S., \& Vlaev, L. T. (2008). Non-isothermal dgradation kinetics of filled with rice husk ash polypropene composites. Express Polymer Lett., 2, 133-146. http://dx.doi.org/10.3144/expresspolymlett.2008.18

Turmanova, S., Dimitrova, A., \& Vlaev, L. (2008). Comparison of water absorption and mechanical behaviours of polypropylene composites filled with rice husks ash. Polymer-Plastics Technol. Eng., 47, 809-818. http://dx.doi.org/10.1080/03602550802188706

Turmanova, S. Ch., Dimitrova, A. S., \& Vlaev, L. T. (2008). Study of polypropene composites filled with rice husk ash. Oxidation Comm., 31, 465-481.

Vlaev, L., Turmanova, S., \& Dimitrova, A. (2009). Kinetics and thermodynamics of water adsorption onto rice husks ash filled polypropene composites. J. Polym. Res., 16, 151-164. http://dx.doi.org/10.1007/s10965008-9213-3

Vlaev, L., Turmanova, S., \& Genieva, S. (2009). Chapter 11. Products and applications of pyrolyzed rice husks: structure, morphology, thermal, kinetics and physicomechanical characteristics. In Pyrolysis: Types, Processes, and Industrial Sources and Products, pp. 267-323, Eds.: W.S. Donahue and J.C. Brandt, New 
York: Nova Science Publishers.

Vlaev, L., Petkov, P., Dimitrov, A., \& Genieva, S. (2011). Cleanup of water polluted with crude oil or diesel fuel using rice husks ash. J. Taiwan Inst. Chem. Eng., 42, 957-964. http://dx.doi.org/10.1016/j.jtice.2011.04.004

Wang, D., \& Sun X. S. (2002). Low density straw particle board. Industrial Crops and Products, 15(1), 43-50. http://dx.doi.org/10.1016/S0926-6690(01)00094-2

Watari, T. Tsubira, H. Torikai, T. Yada, M. \& Furuta, S. (2003). Preparation of porous carbon/silica composites from rice husk powder. J. Ceram. Proc. Res., 4, 177-180.

Watari, T., Nakata, A., Kiba, Y., Torikai, T., \& Yada, M. (2006). Fabrication of porous $\mathrm{SiO}_{2} / \mathrm{C}$ composite from rice husk. J. Eur. Ceramic Soc., 26, 797-801. http://dx.doi.org/10.1016/j.jeurceramsoc.2005.06.013

Weis, E. M., \& Wilke, W. (1992). Structure and mechanical behaviour of short glass fibre-reinforced ethylenetetrafluoroethylene copolymers Part II. Description of the mechanical behaviour using rheological models. $J$. Mater. Sci., 27, 1883-1891. http://dx.doi.org/10.1007/BF01107216

Yang, H. S., Kim, H. J., Son, J., Park, H. J., Lee, B. J., \& Hwang, T. S. (2004). Rice-husk flour filled polypropylene composites; mechanical and morphological study. Composite Structures, 63, 305-312. http://dx.doi.org/10.1016/S0263-8223(03)00179-X

Yang, H. S., Kim, H. J., Park, H. J., Park, H. J., Lee, B. J., \& Hwang, T. S. (2007). Effect of compatibilizing on rice-husk flour reinforced polypropylene composites. Composite Structures, 77, 45-55. http://dx.doi.org/10.1016/j.compstruct.2005.06.005

Yang, H. S., Wolcott, M. P., Kim, H. S., Kim, S., \& Kim, H. J. (2006). Properties of lignocellulosic material filled polypropylene bio-composites made with different manufacturing processes. Polymer Testing, 25, 668-676. http://dx.doi.org/10.1016/j.polymertesting.2006.03.013

Yang, H. S., Kim, D. J., \& Kim H. J. (2003). Rice straw-wood particle composite for sound absorbing wooden construction materials. Bioresource Technology, 86(2), 117-121. http://dx.doi.org/10.1016/S09608524(02)00163-3

Yao, F., Wu, Q., Lei, Y., \& Xu, Y. (2008). Rice straw fiber-reinforced high-density polyethylene composite: Effect of fiber type and loading. Industrial Crops and Products, 28, 63-72. http://dx.doi.org/10.1016/j.indcrop.2008.01.007

Yun, C. H., Park, Y. H., \& Park, C. R. (2001). Effect of pre-carbonization on porozity development of activated carbons from rice straw. Carbon, 39, 559-567. http://dx.doi.org/10.1016/S0008-6223(00)00163-9

Zaky, R. R., Hessien, M. M., El-Midany, A. A., Khedr, M. H., Abdel-Aal, E. A., \& El-Barawy, K. A.(2008). Preparation of silica nanoparticles from semi-burned rice straw ash. Powder Technology, 185, 31-35. http://dx.doi.org/10.1016/j.powtec.2007.09.012

Zurina, M., Ismail, H., \& Bakar, A. A. (2004). Rice husk powder-filled polystyrene/styrene butadiene rubber blends. J. Appl. Polymer Sci., 92, 3320-3332. http://dx.doi.org/10.1002/app.20321 